\title{
WestVirginiaUniversity
}

THE RESEARCH REPOSITORY @ WVU

Graduate Theses, Dissertations, and Problem Reports

2003

\section{Utilization of *assessment by Maryland Cooperative Extension faculty}

Jennifer Thorn Bentlejewski

West Virginia University

Follow this and additional works at: https://researchrepository.wvu.edu/etd

\section{Recommended Citation}

Bentlejewski, Jennifer Thorn, "Utilization of *assessment by Maryland Cooperative Extension faculty" (2003). Graduate Theses, Dissertations, and Problem Reports. 2527.

https://researchrepository.wvu.edu/etd/2527

This Dissertation is protected by copyright and/or related rights. It has been brought to you by the The Research Repository @ WVU with permission from the rights-holder(s). You are free to use this Dissertation in any way that is permitted by the copyright and related rights legislation that applies to your use. For other uses you must obtain permission from the rights-holder(s) directly, unless additional rights are indicated by a Creative Commons license in the record and/ or on the work itself. This Dissertation has been accepted for inclusion in WVU Graduate Theses, Dissertations, and Problem Reports collection by an authorized administrator of The Research Repository @ WVU.

For more information, please contact researchrepository@mail.wvu.edu. 


\title{
Utilization of Assessment by Maryland Cooperative Extension Faculty
}

\author{
Jennifer Thorn Bentlejewski
}

Dissertation submitted to the College of Human Resources and Education at West Virginia University in partial fulfillment of the requirements for the degree of

\author{
Doctor of Education \\ in \\ Educational Leadership Studies \\ Elizabeth Jones, Ph.D., Chair \\ Richard Hartnett, Ed.D. \\ Ernest Goeres, Ph.D. \\ Richard Walls, Ph.D. \\ Nancy Priselac, Ed.D. \\ Department of Advanced Educational Studies \\ Morgantown, West Virginia \\ 2003
}

Keywords: Assessment, Learning Outcomes, Accountability, Cooperative Extension

Copyright 2003 Jennifer T. Bentlejewski 


\section{ABSTRACT \\ Utilization of Assessment by Maryland Cooperative Extension Faculty \\ Jennifer Thorn Bentlejewski}

The research study explored the degree of faculty utilization of assessment practices at the class, program, and institutional levels within the University of Maryland Cooperative Extension. Differences in assessment utilization among faculty of various ranks and disciplines were examined. Faculty perceptions of the benefits and challenges of implementing assessment were also investigated. A quantitative research approach guided the study, which utilized a 78-item survey. Descriptive statistics, multivariate analyses of variance, and analyses of variance were used to analyze the quantitative data. In addition to the survey instrument, a qualitative analysis of data was conducted with regard to learning outcomes and assessment instruments submitted by faculty.

Four specific elements of assessment served as the basis for investigating faculty utilization of assessment. The descriptive data revealed that faculty were utilizing a number of effective practices with regard to developing learning outcomes, designing assessment measures, creating learning experiences, and using the results of assessment. In terms of differences in utilization with regard to faculty discipline, the inferential statistics uncovered statistically significant differences in developing learning outcomes and using assessment measures. In terms of disparities in assessment utilization based on rank, no significant differences were found. The investigation of faculty perceptions revealed countless benefits of assessment as well as a number of challenges.

This study resulted in findings which could serve as catalysts for additional research endeavors in assessment of student learning in higher education. The results of the study should enable administrators and assessment leaders to develop more effective strategies for encouraging faculty involvement in assessment efforts. This in turn could lead to successful initiatives to improve educational programs as well as accountability efforts within institutions of higher education. 


\section{ACKNOWLEDGEMENTS}

The successful completion of this dissertation would not have been possible without the support of a number of key people in my life. I need to sincerely thank each of these individuals for all of their encouragement throughout this process.

I would like to thank my doctoral committee members for lending their expertise to this endeavor. Thanks to Dr. Elizabeth Jones, my committee chair, who provided me with an exceptional foundation to conduct this study. The vast amount of time and skill that she dedicated to this venture was unparalleled. I would also like to thank Dr.

Richard Hartnett who offered the insight that I needed to persevere. Thanks to Dr. Ernest Goeres for kindly directing me through the logistics of the dissertation process. I want to thank Dr. Richard Walls for his statistical expertise in the analyses. Lastly, I must extend my appreciation to Dr. Nancy Priselac who provided invaluable advice and guidance.

The support and compassion of my family throughout the doctoral program has been absolutely immeasurable. I want to sincerely thank my husband, Jeff, who never lost confidence in me and who provided the constant encouragement that I needed to finish. I also want to express gratitude to my parents, Donald and Carolyn, who instilled in me the necessary values and discipline needed to accomplish any goal. Without these three people in my life, I would have not been able to achieve this ambition.

Finally, I would like to thank my friends who provided motivation, including my colleagues in Maryland Cooperative Extension. Thanks to members of the doctoral cohort for the great camaraderie over the years. I am especially grateful for two very special people in the cohort, Billie and Ester, whose friendship enabled me to persist against the odds. 
Table of Contents

Chapter 1. Problem Statement 1

Purpose 4

Chapter 2. Review of Literature $\quad 6$

Research Framework $\quad 6$

Dual Purpose of Assessment $\quad 7$

Effective Assessment Practices $\quad 9$

Articulating Intended Learning Outcomes 9

Selecting Data Gathering Measures 13

Designing Effective Learning Experiences $\quad 14$

Discussing and Using Assessment Results 16

Assessment within Cooperative Extension $\quad 18$

Challenges of Implementing Assessment 23

Benefits of Implementing Assessment $\quad 30$

Definition of Key Terms and Concepts 35

$\begin{array}{ll}\text { Chapter 3. Method } & 37\end{array}$

$\begin{array}{ll}\text { Population } & 37\end{array}$

Research Design $\quad 38$

Pilot Study $\quad 40$

Data Collection $\quad 50$

Data Analysis $\quad 50$

Chapter 4. Results $\quad 54$

Population and Sample $\quad 54$

Demographic Data $\quad 55$

$\begin{array}{ll}\text { Research Questions } & 57\end{array}$

Research Question One- Utilization of Assessment 58

Research Question Two- Benefits of Assessment 75

Research Question Three- Challenges of Assessment $\quad 78$

Research Question Four- Use of Assessment Results 83

Research Question Five- Difference Across Disciplines $\quad 86$

Research Question Six- Difference Across Ranks 93

Chapter 5. Summary, Conclusions, and Recommendations 95

$\begin{array}{ll}\text { Summary } & 95\end{array}$

$\begin{array}{ll}\text { Conclusions } & 97\end{array}$

Assessment Perceptions $\quad 97$

Assessment Practices $\quad 100$

Recommendations for Future Research 104

Recommendations for Future Practice 107 
Appendixes
A. Permission Letter to Conduct Study

B. Pilot Cover Letter to Participants

C. Pilot Survey of Assessment Utilization by Extension Faculty 124

D. Cover Letter to Pilot Participants

E. Pilot Study Interview Questions

F. Final Version of Cover Letter to Participants 130

G. Survey of Assessment Utilization by Extension Faculty 132 
List of Tables

Table 1. Main Programmatic Focus of Faculty 56

Table 2. Professorial Rank of Faculty $\quad 57$

Table 3. Development of Class Level Outcomes by Faculty 60

Table 4. Development and Use of Program Level Outcomes by Faculty 64

Table 5. Development and Use of Organizational Level Outcomes by Faculty 66

Table 6. Use of Assessment Measures by Faculty 68

Table 7. Types of Assessment Measures Developed by Faculty 70

Table 8. Examples of Measures in Each Domain Developed by Faculty 71

Table 9. Development of Educational Experiences by Faculty 74

Table 10. Faculty Perceptions of the Benefits of Assessment 76

Table 11. Faculty Perceptions of the Challenges of Assessment 79

Table 12. Uses of Assessment Results by Faculty 85

Table 13. Outcome Practices Among Faculty of Different Disciplines 88

Table 14. Assessment Measure Practices by Faculty Discipline 91 


\section{CHAPTER 1}

\section{Problem Statement}

As the demand for accountability and improvement in higher education continues to intensify, effective assessment programs have become ever-increasingly essential. The need for assessment in higher education was brought to the attention of educators as well as the public in the mid 1980s (Palomba \& Banta, 1999). This increased awareness was initiated by four reports that addressed the need for higher education reform (Ewell, 1991). The assessment efforts that followed at universities and colleges were mostly driven by external accountability forces, such as policy initiatives from state government (Ewell, 1993). By the early 1990s, a separate assessment focus arose with regard to improving learning and teaching in higher education (Huba \& Freed, 2000). Although initial pressures for assessment were related to accountability, most higher education institutions now concentrate their assessment efforts on improving student learning (Banta, 1993b).

With this focus on learning, faculty must review more closely the design and implementation of their curricula. The transition from a teaching-centered paradigm to a learner-centered paradigm challenges faculty to reexamine their roles and the roles of students in the learning process (Huba \& Freed, 2000). As faculty initiate changes in their teaching strategies to improve student learning, it is essential that provisions be made to assess if and how their teaching modifications are making a difference.

Generally, assessment is a process that gathers feedback from an educational effort and acts upon that information (Huba \& Freed, 2000). The action ideally leads to improvement in teaching as well as student learning. To understand how educational 
programs are functioning and whether or not they are contributing to student growth is the main goal of assessment in institutions of higher education (Palomba \& Banta, 1999). Huba and Freed (2000) define assessment as:

The process of gathering and discussing information from multiple sources in order to develop a deep understanding of what students know, understand, and can do with their knowledge as a result of their educational experiences; the process culminates when assessment results are used to improve subsequent learning. (p. 8)

As the assessment movement in higher education forced faculty to reexamine their priorities, roles and responsibilities with regard to assessment have become more apparent. Widespread involvement of faculty is probably the most essential factor in the development of successful assessment programs (Palomba \& Banta, 1999). According to Hadden and Davies (2002, p. 244), faculty must "own and drive" the assessment process to ensure meaningful results. Faculty assessment responsibilities vary from roles such as assessment coordinators to members of assessment committees. Other faculty participate in assessment by administering instruments, analyzing data or writing assessment reports (Palomba \& Banta, 1999).

Although faculty should be involved in all steps of the process, their resistance is a reality. Since assessment was initially introduced by external agencies as an accountability directive, a number of faculty are still reluctant to become involved in assessment efforts (Huba \& Freed, 2000). Despite initiatives at universities to support development and rewards, faculty still remain resistant (Palomba, 1997). Many faculty 
perceive assessment to be an inflexible and immense process which should be divided into manageable units and implemented on a trial basis (Gray, 1997).

Other reasons for faculty resistance include cost, time, fear of how the information will be used, and the threat to academic freedom (Palomba \& Banta, 1999). Some faculty also experience difficulty in understanding and using the process due to its terminology and complex procedures (Gray, 1997). Although some professors continue to resist assessment, "for the foreseeable future, the need to document what students are accomplishing as a result of their college experience will increase rather than subside" (Banta, 1993a, p. 374).

These assessment challenges are apparent throughout the various components of higher education institutions. One such component in land grant universities is the Cooperative Extension System which provides lifelong education through a partnership with the United States Department of Agriculture and local county governments (White \& Burnham, 1995). This adds two additional levels to the typical accountability element of assessment since Cooperative Extension is accountable not only to the state legislature, but to the federal and county governmental bodies as well.

There is a lack of empirical evidence regarding how and to what extent higher education institutions are conducting outcomes assessment (Peterson \& Einarson, 2001). Although there are a few studies related to the use of assessment by faculty in higher education, most of the literature relates specifically to academic programs. There is a lack of research about the utilization of assessment by Cooperative Extension faculty. As support for this study's examination of faculty perceptions related to assessment 
utilization, Gray (1997) noted that in order to determine the success of an assessment program, the unit of analysis should be the individual faculty, not the entire institution.

\section{Purpose}

This study examined the existing assessment practices of faculty within the University of Maryland Cooperative Extension (MCE) by exploring the degree of faculty utilization of assessment practices at the class, program, and institutional levels. The study explored the differences in assessment utilization among faculty of various ranks and disciplines. This inquiry also identified what faculty believed were the benefits and challenges of implementing assessment. Finally, how faculty used the results of assessment to make improvements was examined.

Through this investigation, a more thorough understanding of faculty involvement in assessment efforts in Cooperative Extension was gleaned. This examination of assessment benefits and challenges can enable administrators and assessment leaders to develop more effective strategies for garnering and securing faculty support for and involvement in assessment efforts. This enhancement of faculty involvement could lead to successful assessment efforts to improve educational programs as well as accountability efforts within Cooperative Extension. This research could also be useful for other higher education leaders and faculty to relate the results to their own educational programs.

The following research questions were explored in this study:

1. To what degree are Cooperative Extension faculty utilizing assessment at the class, program, and institutional levels?

2. What do faculty perceive to be the benefits of implementing assessment? 
3. What do faculty perceive to be the challenges of implementing assessment?

4. How do faculty use the results of assessment to make improvements?

5. Is there a statistically significant difference among faculty across disciplines (agriculture, youth development, and family and consumer sciences) regarding their utilization of assessment?

6. Is there a statistically significant difference among faculty across different ranks (full professor-principal agent, associate professor-senior agent, assistant professor-agent) regarding their utilization of assessment?

This chapter has outlined the background of the problem, significance of the study, and the research questions. Chapter 2 presents the review of literature related to assessment practices and principles as well as faculty involvement and utilization of assessment. Chapter 3 describes the research design that was used to explore the research questions. The chapter explains the research methods which includes a description of the population, research design, data collection procedures, and analysis. Chapter 4 presents the results of this assessment research study. The emphasis of the chapter is on the statistical analyses of the data for the six research questions. Chapter 5 serves as the conclusion to the study. It includes a discussion of the major findings as they relate to the assessment literature. Recommendations for future research and practice are discussed. In the Appendixes, the cover letters and the instrument are included. 


\section{CHAPTER 2}

\section{Review of Literature}

The literature review examines the use of effective assessment practices in higher education institutions. This review begins by exploring the dual purpose of assessment which is accountability and improvement. Second, research related to faculty utilization of effective assessment practices in higher education is examined. Next, Cooperative Extension literature related to the utilization of assessment is reviewed. Finally, the benefits and challenges of implementing assessment are investigated.

Based on the extensive literature review that follows, the conceptual framework in Figure 1 has been created to guide the inquiry.

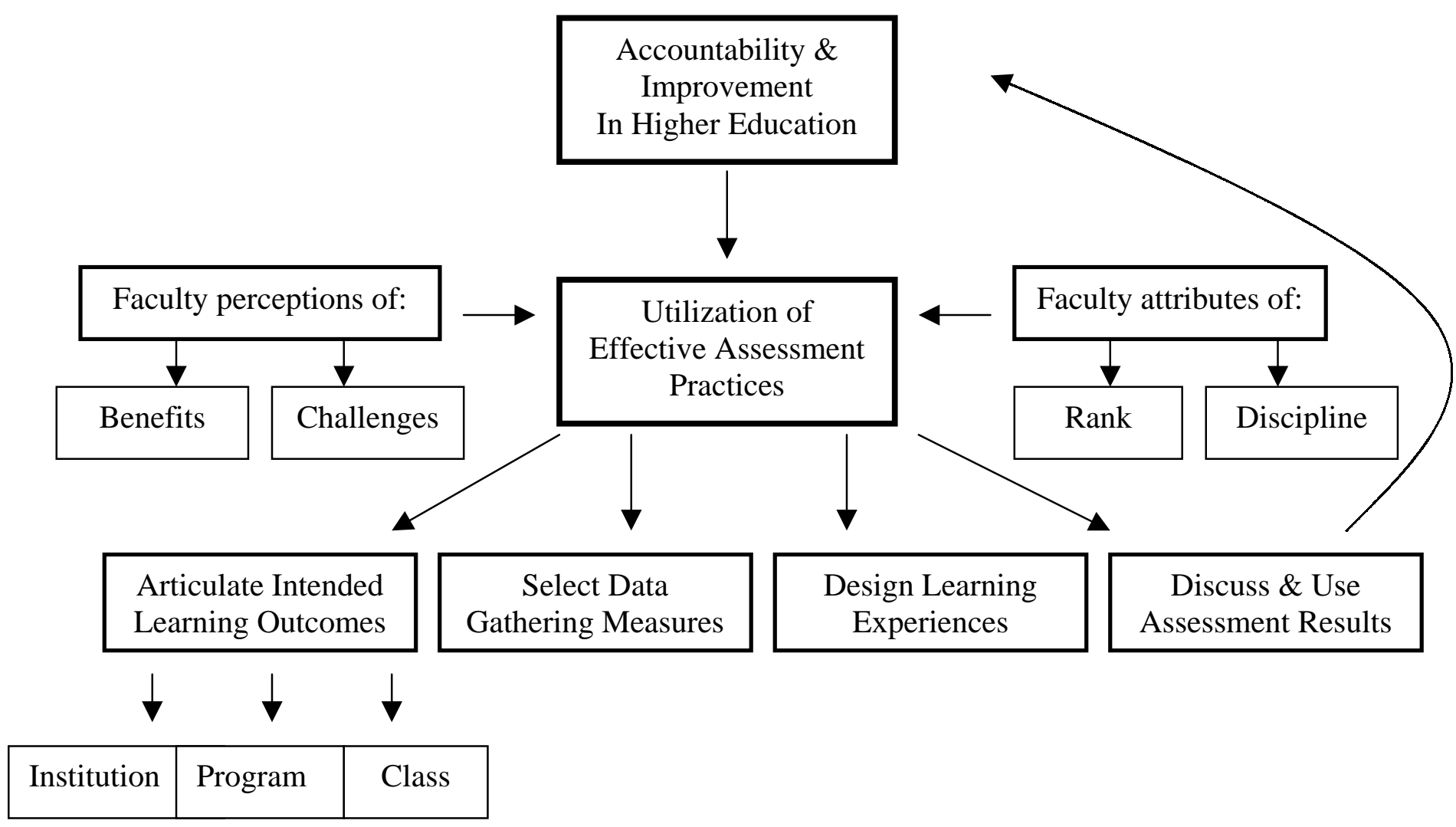

Figure 1. Research framework. 
The word "assessment" has been interpreted in a number of ways since the start of the assessment movement. For purposes of this review, assessment is defined as a process that gathers data from various sources to determine how students' knowledge, attitudes, and behaviors have changed as a result of their experiences (Huba \& Freed, 2000). It is important to note that assessment involves more than just a simple set of techniques but also requires a cultural shift among administration, faculty, and students within the institution. Assessment helps identify the deficits that exist between actual and intended results so that opportunities for improving the quality of higher education (Pike, 2002) and demonstrating accountability can be achieved.

\section{Dual purpose of assessment}

At the start of the assessment movement, external accountability forces mostly drove the assessment efforts at institutions of higher education. These forces were influential because higher education institutions receive financial support from local, state, and federal governments in addition to tuition and other sources. Clearly, accountability efforts are vital since institutions have responsibility to the supporters to demonstrate that the institutional goals are being achieved (Jacobi, Astin, \& Ayala, 1987). Using assessment for accountability purposes allows for the successes to be showcased in order to convince constituencies that funds are being well spent and that no changes are necessary (Huba and Freed, 2000).

Although initial pressures focused on accountability, internal forces within institutions began to concentrate on improvement which examines both strengths and weaknesses of programs. The basis of these internal pressures centers around the development of coherent curricula that can be manipulated and improved through 
continuous assessment of student learning (Ewell, 2002). In order for this type of assessment to lead to improvement, the process "must reflect what people are passionate about, committed to, and value" (Banta, Lund, Black, \& Oblander, 1996, p. 5).

Evidence of the internal pressures was demonstrated in a study of 73 NASULGC member institutions conducted in 1990. Only 13 institutions were conducting assessment with accountability as their main goal; 23 were using assessment for program improvement or student performance improvement; and 23 were implementing assessment for both effectiveness and improvement (Muffo, 1992). The remaining institutions reported conducting assessment for purposes other than improvement or accountability. This study points out an important distinction in assessment for improvement. Assessment can be used for improving student learning which has been seen to be an organized and systematic process, in comparison to assessment for improving programs which, in some documented cases, tends to be more unorganized and less prevalent (Williford, 1997).

Based on this assessment literature and research, it is apparent that institutions of higher education implement assessment for both purposes of demonstrating accountability and improving programs. The improved learning that results from assessment should satisfy external constituencies so that accountability can be an integral part of the improvement process (Huba \& Freed, 2000). A study of 33 large research universities found that $80 \%$ of the institutions were conducting assessments for the purposes of improving teaching and learning as well as verifying organizational effectiveness (Ory \& Parker, 1989). Palomba and Banta (1999) also recognized that the 
two purposes should not be considered as two totally separate reasons for conducting assessment.

\section{Effective Assessment Practices}

Huba and Freed (2000) identified four essential elements of assessment which will serve as the basis for this inquiry into effective assessment practices utilized by faculty. First, faculty should formulate statements of intended learning outcomes which express what the learners should "know, understand, and be able to do with their knowledge" (Huba \& Freed, 2000, p. 10). Since these outcomes must be clear and specific enough to measure, the second vital assessment practice is the development of data gathering measures to determine whether or not the learning outcomes are reached. The third element of successful assessment emphasizes the importance of integrating assessment into planning the curriculum at the program and class levels. This component involves creating experiences through an innovative curriculum to help ensure the attainment of the intended outcomes (Huba \& Freed, 2000). The final element of assessment that will be examined is that of "discussing and using assessment results to improve learning" (Huba \& Freed, 2000, p. 14). This section of the literature review will be organized around these four elements of assessment.

\section{Articulating Intended Learning Outcomes}

The first essential element of formulating intended learning outcomes involves describing what students should know and be able to do following an educational experience. The American Association for Higher Education (AAHE) developed nine principles of good practice for assessing student learning, many of which closely relate to creating learning outcomes. The principle of "assessment works best when the programs 
it seeks to improve have clear, explicitly stated purposes" (AAHE, 1992, para. 3) relates to the need for specific outcomes. Since outcomes require forethought regarding expectations of students, the need for clarity outlined in this principle is achieved through proper learning outcome development.

When creating the outcomes, another assessment principle, "assessment makes a difference when it begins with issues of use and illuminates questions that people really care about" (AAHE, 1992, para. 7), is a necessary element to consider. It is essential that the outcomes be linked to significant and valuable aspects of learning. Also, considering the institution's mission and values is fundamental in the development of intended learning outcomes (Huba \& Freed, 2000). This is a reflection of the first principle of good practice for assessing student learning outlined by the AAHE which is "assessment of student learning begins with educational values" (AAHE, 1992, para. 1). This principle stresses the importance of connecting assessment to the institution's mission, values and goals.

Developing these outcomes sets the stage for the program planning and assessment processes. When learning outcomes are proposed prior to the implementation of a program, it forces the assessment process to be a vital component of program planning and not something that happens when a program is completed. The development of these outcomes also leads to improved clarity with regard to the program prior to delivery (Cote \& Jordan, 2002).

Higher education institutions should make the development of learning outcomes a top priority for faculty, administrators, and students so that the institutional focus is truly on student learning and achievement (Eisenman, 1991). The emphasis on student 
learning must be the basis for the development of the outcomes. They must be formulated to be student-centered which involves moving away from the teacher-centered paradigm where the focus is on simple transmission of knowledge to students. Brakke and Brown (2002) claim that if institutions would concentrate more on student learning, a cultural shift would occur allowing the use of effective assessment practices.

The focus of learning outcomes must be on the attainment of critical skills as well as abilities that endure over time. The learning outcomes should address multiple dimensions of learning including concepts or facts, attitudes, and application (Banta et al., 1996). Ewell (1983) stated that outcomes have been used by institutions to depict a wide array of student functioning ranging from short-term cognitive development to long-term behavior changes.

One student learning domain that is used in the development of intended learning outcomes is the cognitive domain. These cognitive measures have been the typical focus of educational assessment in the past. Cognitive intended learning outcomes center around students' thinking skills (Palomba \& Banta, 1999). Bloom (1956) identified six levels of cognitive learning which become increasingly complex at the higher levels. The first level is demonstrated by simple knowledge or recall through remembering previously learned material. Comprehending the information by classifying, describing, and identifying it constitutes the second cognitive level. Bloom's next level includes being able to apply and use the knowledge in concrete situations. Analyzing and breaking the material down represents the fourth cognitive level. Being able to synthesize and arrange the knowledge components is Bloom's fifth level. Finally, 
judging the value of the material through evaluation is the sixth cognitive level. Learning outcomes can be developed at all of these levels of the cognitive domain.

In order to verify the impacts of higher education on learners, assessment efforts must go beyond simple measurement of cognitive outcomes (RiCharde, Olney, \& Erwin, 1993). Typically, affective outcomes are based on a person's predisposition to behave in a particular way based on emotions, attitudes, and values (Huba \& Freed, 2000).

Examples of affective outcomes include behaving in an ethical manner, being cognizant of other people's values, and exhibiting leadership abilities (Palomba \& Banta, 1999).

Krathwohl, Bloom, and Masia (1964) described the affective domain through a classification system with a continuum based on degrees of the learners' internalization. The lowest level in the affective domain is receiving which involves the learner being aware of specific ideas through differentiation or acceptance. The next level requires the learner to actively respond to certain information. Being concerned about the worth of a particular idea through valuing it is the third affective level. Next, relating the value to previously held values is what Krathwohl and Associates termed organization. The highest level is characterization which includes the learner internalizing values. The affective outcomes are "more subtle and consequently often more difficult to assess, but they are no less important" to the institution (Ewell, 1983, p.13).

Both cognitive and affective outcomes tend to be long lasting in the development of learners (RiCharde et al., 1993). Although these outcomes have been shown to be enduring, most institutions are simply collecting student satisfaction data instead of cognitive or affective information (Peterson \& Einarson, 2001). For example, $80 \%$ of the institutions were collecting data about students' basic skills in comparison to only $34 \%$ 
collecting higher order information about cognitive thinking and 35\% about students' affective development (Peterson \& Einarson, 2001).

The third student learning domain is psychomotor learning which includes learners' performance demonstrated by physical functions, movements, and manipulations (Palomba \& Banta, 1999). This domain incorporates the "development of muscular skills and neuromuscular coordination" (Huba \& Freed, 2000, p. 112). Assessment of these behaviors provides profound information about what students are actually doing with the knowledge that they have gained from their educational experiences. Unfortunately, psychomotor outcomes are the least often assessed in higher education institutions (Ewell, 1983).

Not surprisingly, a study by Ory and Parker (1989) found that there is an overall absence of organizational efforts aimed at assessing student-learning outcomes in all three domains. When developing intended learning outcomes, it is essential to focus on outcomes that encompass all three learning domains (Huba \& Freed, 2000). This integrated approach to the development of learner outcomes should be utilized at the institutional, program, and course levels (Huba \& Freed, 2000). Selecting Data Gathering Measures

In order to determine if the learning outcomes have been reached, data gathering measures should be appropriately designed or selected. This is the second essential element of a successful assessment process outlined by Huba and Freed (2000). It is also echoed in AAHE's principle of "Assessment is most effective when it reflects an understanding of learning as multidimensional, integrated, and revealed in performance over time" (AAHE, 1992, para. 2). 
There are both direct and indirect assessments of student learning that help ensure that faculty fully comprehend whether or not the learning outcomes have been achieved. Direct assessment methods require learners to demonstrate their knowledge and skills as they respond to an instrument (Palomba \& Banta, 1999). Direct assessment methods include examinations with multiple-choice and true-false questions and performance assessments such as presentations, demonstrations, simulations, and portfolios (Palomba \& Banta, 1999).

Indirect assessments focus on self-report measures about what students think they have learned in comparison to direct methods which focus on the demonstration of the knowledge (Huba \& Freed, 2000). Indirect methods include questionnaires, surveys, interviews, and focus groups (Palomba \& Banta, 1999). In order to make appropriate decisions about the learning that has taken place, both direct and indirect assessment methods should be utilized (Huba \& Freed, 2000). A national study found that higher education institutions tend to make more use of traditional assessment methods such as standardized tests than methods like portfolios and capstone courses (Peterson \& Einarson, 2001).

\section{Designing Effective Learning Experiences}

The third vital element of effective assessment efforts, as outlined by Huba and Freed (2000), involves providing opportunities, inside and outside of the classroom, in order to achieve specified learning outcomes. AAHE also claims that "assessment requires attention to outcomes but also and equally to the experiences that lead to those outcomes" (AAHE, 1992, para. 4). These experiences should be planned, designed, and implemented at the course, program, and institutional levels. 
Assessment integration at the course level entails designing appropriate curricula so that the learners can achieve the knowledge and skills described in the intended learning outcomes. An innovative curriculum with an interrelated set of experiences will help ensure outcome attainment (Huba \& Freed, 2000). In essence, assessment involves concentrating on the processes of teaching and curriculum development for the purpose of improving student learning (Banta, 1997).

Successful assessment efforts also require integration of assessment at the program and institutional levels. Browne and Kiernan (1998) reported that the integration of assessment with program planning is critical to achieving outcomes with noticeable impact. Assessment at the institutional level involves broad outcomes that address the "students' understanding of physical and biological properties of the environment" (Huba \& Freed, 2000, p. 108). Findings from a national study of assessment showed that course and program level assessment were more often implemented than were institution-wide assessment activities (Peterson \& Einarson, 2001). It is essential that assessment be more integrated within the institution as a series of linked activities (Banta, 1997) that are part of the everyday organizational practices of the institution (Huba \& Freed, 2000). Integration of assessment into daily life is also one of AAHE's principles of good assessment practice in that "assessment works best when it is ongoing, not episodic" (AAHE, 1992, para. 5).

Attempting to integrate assessment at each level requires faculty to think outside of their disciplines and to examine student learning from a holistic perspective (Magruder, McManis, \& Young, 1997). Schultz (2002) claimed that in an attempt to maintain control of their curriculum, faculty have been manipulating assessment data 
"rather than putting into effect the structural changes necessary to achieve the outcome"

(p. 12). National study findings confirm that higher education institutions are not conducting assessments according to recommendations developed by the assessment scholars (Peterson \& Einarson, 2001).

Discussing and Using Assessment Results

The fourth crucial element of effective assessment, as outlined by Huba and Freed (2000), is discussing and using the assessment results. It is essential that faculty think in advance about whom the assessment results will be shared with and how the results will be used. The first component of discussing the results involves institutions designing ways to discuss and share assessment findings internally with faculty, administrators, and students as well as externally with stakeholders, funders, and employers (Palomba \& Banta, 1999). The actual communication of assessment results helps force action on assessment itself (Pike, 2002).

The other component of using the results is so vital since assessment is often implemented without further dialogue about success or failure. Palomba and Banta (1999) have found a number of linkages between the use of assessment results and internal processes. Internally, assessment data are used for continuous improvement purposes as well as for program review procedures (Palomba \& Banta, 1999). An obvious internal application of assessment results is in the improvement of teaching and learning. It is vital that the results be used in this manner so that faculty and students continue to participate in assessment efforts (Palomba \& Banta, 1999). Information gathered during the assessment process must be incorporated into the way programs are structured (Bush, Mullis, \& Mullis, 1995). Brakke and Brown (2002) reported that if 
curricula adapt in response to assessment results, then the institution becomes a learning organization by making effective use of the results for improvement.

Another critical point in the process is described in the following AAHE assessment principle: "assessment is most likely to lead to improvement when it is part of a larger set of conditions that promote change" (AAHE, 1992, para. 8). Since assessment focuses on change, it is essential that it focus on organizational aspects that can actually be changed (Pike, 2002). One study of NASULGC member institutions indicated that $30 \%$ of the institutions reported changes in programs as a result of assessment efforts (Muffo, 1992).

The usefulness of assessment data is evident when it is used for decision-making purposes at the institution, program, and course levels. A study by Ory and Parker (1989) of large, research universities indicated that universities are in fact using the assessment information for policy decisions. Conversely, a study of 1,393 postsecondary institutions found that student "assessment data has only a marginal influence on academic decision making" (Peterson \& Augustine, 2000, p. 44). The study also found that research institutions use assessment data for academic or faculty decision-making least often in comparison to other Carnegie types of institutions.

Assessment results can be used internally for institutional planning and budgeting processes. In order to systematically incorporate assessment information into planning and budgeting, annual reports should document outcomes which may lead to funding decisions (Palomba \& Banta, 1999). A study at Ohio University revealed that they use assessment results for strategic planning, program planning, program improvement, and curricular review (Williford, 1997). 
Another use of assessment results is in verifying that the assessment process itself has supplied the necessary information (Palomba \& Banta, 1999). One study found that only one-half of the 1,393 institutions surveyed were actually evaluating their own assessment processes (Peterson \& Einarson, 2001). This reexamination of the assessment process involves the consideration of the four attributes of utility, feasibility, propriety, and accuracy (Palomba \& Banta, 1999).

In addition to internal uses of assessment results, the information can also be used for external constituencies. Conducting assessment for external demands has become more common especially due to performance-based funding. Over forty states are now involved with assessing programs with linkages to funding (Schultz, 2002). A study at Ohio University revealed that assessment results are used for external purposes such as securing funding based on performance, meeting statewide mandates for assessment data, and gaining recognition for their attention to quality (Williford, 1997). Assessment results are used for marketing to potential students and employers in the community. The results can also be used to be accountable to stakeholders which reflects one of AAHE's principles of good assessment practice which is "through assessment, educators meet responsibilities to students and to the public" (AAHE, 1992, para. 9).

\section{Assessment within Cooperative Extension}

Assessment is essential throughout all segments of higher education institutions including Cooperative Extension, which has been classified as the "third arm" of land grant universities (Warner \& Christenson, 1984, p. 6). Extension was created in 1914 as part of the Smith-Lever Act as a nationwide outreach program to disseminate information from universities to local people (Prawl, Medlin, \& Gross, 1984). This dissemination of 
research-based knowledge is aimed at improving agricultural practices, conserving natural resources, strengthening family life, and fostering leadership skills among youth (United States Department of Agriculture, 1983).

The Administrative Handbook for Cooperative Extension Work defines Extension's mission as "helping people improve their lives through an educational process which uses scientific knowledge focused on issues and needs" (United States Department of Agriculture, 2002, para.2). Extension education has been defined as "the process of extending useful and practical information through a broad range of methods to persons in out-of-school situations" (Prawl et al., 1984, p. 25).

The Cooperative Extension System includes "74 Land-grant institutions with 32,000 employees based on campuses and in 3,150 counties" (National Association of State Universities and Land-Grant Colleges, 2001, para. 1). The system is publicly funded through a partnership with the United States Department of Agriculture, state land-grant universities, and local county governments. The Extension staff are employees of the land-grant universities and are not employees of any of the three levels of government even though they receive funding from them (Warner \& Christenson, 1984).

In addition to providing funding, each of the three partners has other unique roles that are essential to the operation of the total system. The federal partnership, the United States Department of Agriculture- Cooperative State Research, Education, \& Extension Service, provides national objectives and priorities and performs coordination and accountability functions (White \& Burnham, 1995). The state land-grant universities function as the coordinators in all states working with the federal and local partners to 
initiate, implement, and assess the educational programs (White \& Burnham, 1995). The local partner, who is usually county government, makes certain that local educational needs are being met through Extension education programs. This triad of partners adds to the complexity of assessment within Extension.

The Extension offices, that are located in most every county, are staffed with faculty who serve as the link to research and education at the land grant university in that state. Although Extension has characterized its function as educational, the subject matter and audiences have varied over time (Warner \& Christenson, 1984). These faculty determine the educational needs of citizens of their county in order to plan, implement, and assess their educational efforts.

Typically, there are Extension Educators in almost every county, each of whom has expertise and training in a specific discipline such as agriculture and natural resources, 4-H and youth development or family and consumer sciences. In many states, Extension faculty are part of the tenure system and are faculty within a particular college of the university, usually the College of Agriculture and Natural Resources. For example, at the University of Maryland, Extension faculty are tenured and have the following ranks: full professor- principal agent, associate professor- senior agent, and assistant professor- agent. There appears to be a lack of literature regarding how these two factors, discipline and rank, affect Extension faculty utilization of assessment.

The individual class planning and assessment process is designed to affect learners' knowledge, attitudes, and ultimately their behavior. In order to change the learners' behavior, the classes are typically designed as numerous educational experiences that go beyond single, isolated in-services or presentations. In essence, an 
Extension class can be defined as a coordinated arrangement of learning experiences aimed at affecting the knowledge and behaviors of participants in order to address identified community needs.

Demonstrating the impact of these learning experiences through assessment has become increasingly important to university administrators and external funders of Extension (Bailey \& Deen, 2002). The focus on assessment in Extension for accountability as well as improvement was set into motion in the late 1970's by the Food and Agriculture Act and the Extension Committee on Organization and Policy (Warner \& Christenson, 1984). The General Accounting Office also released a study in 1981 that questioned the mission of Extension (Warner \& Christenson, 1984). The release of these reports led Extension in a new direction with regard to examining its effectiveness.

There has been a shift in assessment standards which cannot be reached by traditional measures of just effort and accomplishment. The assessment movement has created a culture that is no longer concerned about how much happened in the classroom, but about what noticeable differences occurred with learners (Rosenthal, 2000). It was previously believed that if an Extension program was implemented and people were reached, then the program was effective (Warner \& Christenson, 1984). With budgets continuing to tighten, it is apparent that obtaining information about what clientele learn and do with the knowledge is essential for Extension's survival. The strategy is moving from merely counting the number of participants to measuring program outcomes and impacts that demonstrate behavior changes in the clientele population that are attributable to the educational programs (Warner \& Christenson, 1984). 
Every Extension program should have specified educational outcomes which address the intended positive changes for learners (Prawl et al., 1984). In Extension, the continuum for assessing learners ranges from casual observations to planned scientific research (Prawl et al., 1984). Arnold (2002) also contended that Extension faculty should be focusing their efforts on the assessment of the learning of their program participants. In order to assess learning, measurable learning outcomes must first be developed (Arnold, 2002). When the learning outcomes have been articulated by the Extension Educators, the assessment process can go forward.

A small number of studies exist with regard to the utilization of assessment within Extension. A national study by West Virginia University (1979) interviewed 240 Extension agents and surveyed another 1,790 regarding their evaluation practices. Evaluation was defined similarly to assessment since it was described as a process that provided information used to improve programs as well as serve accountability functions (West Virginia University, 1979).

The study found that assessment results were used to influence a number of decisions made within Extension. First, $86 \%$ of faculty felt that assessment results were used to improve existing programs while only $33 \%$ felt that the data were used in administrative decision-making (West Virginia University, 1979). The study also found that there were tensions within Extension regarding the increasing emphasis placed on assessment efforts from external sources (West Virginia University, 1979).

This 1979 study appears to be the most recent appraisal of overall assessment practices in Extension. Another study by Chapman-Novakofski and Associates (1997) examined assessment practices within Extension but used a small sample size that 
included only 26 field faculty from 12 states and 53 nutrition specialists from 47 states. Also, this study only examined perceptions of Extension faculty in a single discipline without regard to rank.

\section{Challenges of Implementing Assessment}

There are a number of challenges that impede the implementation of assessment at institutions of higher education. First and foremost, faculty acceptance of assessment is necessary for success and may not be achieved until they feel some sense of ownership. This sense of ownership can be achieved through faculty involvement in all steps of the assessment process including the initial decision to carry out assessment within the institution (Eisenman, 1991). Faculty should then be involved with the development of the purpose, definitions, and areas of inquiry for assessment (Palomba \& Banta, 1999). Throughout all of the steps, teamwork is essential and should involve faculty, staff, administration, and students (Palomba \& Banta, 1999). Muffo's (1992) study of 73 NASULGC member institutions found that the involvement of faculty in the development and implementation of assessment plans was in the top five of all critical assessment issues identified. It is so critical because initiation of assessment is a cultural shift that often represents significant and substantial modifications in how faculty operate on a daily basis (Eisenman, 1991).

Every faculty member should have some type of assessment role or responsibility. Since the level of involvement in the process varies, faculty can participate by attending meetings; developing learner outcomes; designing assessment instruments; analyzing and interpreting results; reviewing assessment plans; and writing reports (Palomba \& Banta, 1999). Evidence of this was demonstrated by a national study of higher education 
institutions which found that $58 \%$ had assessment committees directed by faculty members (Peterson \& Einarson, 2001).

The fact that assessment is an additional responsibility that faculty are being asked to take on without additional compensation or recognition (Banta, 1997) oftentimes serves as a barrier to implementation. Faculty lose interest when they attempt to implement assessment and receive no rewards for their efforts. Banta and Associates (1996) described this as professional sensitivity toward assessment.

In addition, faculty enjoy the sense of security of their regular routines and habits of their positions (Hadden \& Davies, 2002) and often are resistant to change without incentives. Rosenthal (2000) reported that utilization of assessment can be hindered by the mere fact that many faculty have been long-time members of a system that values outputs such the number of articles or books published instead of gains in student learning. Evidence of lack of rewards was seen in a national study where only $27 \%$ of institutions use some type of incentives for academic units to participate in assessment efforts (Peterson \& Einarson, 2001).

Another common hindrance to successful implementation of assessment is the lack of resources for faculty to become proficient in assessment techniques. A study of Extension faculty found that $42 \%$ of faculty reported lack of skills in the area of assessment which served as a barrier to implementation (West Virginia University, 1979). In order for faculty to become skilled in assessment, materials such as assessment newsletters and manuals must be made available throughout the institution (Palomba \& Banta, 1999). Resources must also be offered for faculty to improve their assessment abilities through off-campus assessment conferences as well as workshops and retreats on 
campus (Palomba \& Banta, 1999). In terms of offering professional opportunities to learn more about assessment, over $41 \%$ of institutions provide some type of assessment training through symposia or retreats (Peterson \& Einarson, 2001).

The expense of conducting assessment has been identified as a challenge to successfully implementing assessment. For example, conducting effective assessment may require release time for faculty which necessitates financial support (Banta et al., 1996). Resources also need to be allocated to cover either the development of local instruments or the purchase of standardized tools. In order to support faculty efforts, resources need to be put in place to provide secretarial support related to data entry and logging of surveys (Palomba \& Banta, 1999). The cost of assessment in combination with increased funding pressures was the most frequently mentioned problem with assessment in a study by Muffo (1992). Extension faculty also cited the cost of assessment as a barrier to implementation according to a study by Chapman-Novakofski and Associates (1997).

In addition to the cost of assessment, the time necessary to implement assessment efforts is also seen as an obstacle (Banta et al., 1996). An Extension study found that $64 \%$ of faculty claimed that they had insufficient time to implement assessment (West Virginia University, 1979). Another study of Cooperative Extension faculty found that only $48 \%$ of faculty spend between 11 to $25 \%$ of their time on assessment (ChapmanNovakofski et al., 1997). The barriers relate to the lack of time for studying assessment through workshops and conferences and the lack of time in carrying out major assessment projects. 
The time commitment, involved in implementing assessment, was identified by faculty as a critical issue in the NASULGC study (Muffo, 1992). Some faculty feel that the time and money spent on assessment efforts could be better spent doing more work and improving on their own (Banta, 1997) while others feel that assessment efforts simply detract from covering the necessary content of their courses (Eisenman, 1991).

Lack of support from administration for assessment can also serve as a challenge to implementation. When there is a lack of involvement by administration, faculty view the process as an additional responsibility done for accountability purposes (Hadden \& Davies, 2002). Leaders need to make assessment an educational issue rather than an accountability matter to combat faculty resistance (Eisenman, 1991). In terms of administrative cooperation, "assessment is most effective when undertaken in an environment that is receptive, supportive, and enabling" (Banta et al., 1996, p.62). This is an essential assessment principle that has been recommended as the tenth AAHE principle of good practice and focuses on effective leadership and administrative commitment (Banta et al., 1996). There is not enough focus on this critical step in assessment which involves utilizing administrative leadership to guide faculty through the acceptance and utilization of the assessment process (Hadden \& Davies, 2002). "Words of support for assessment count only if backed by actions in creating a culture conducive to implementing a useful and used assessment program" (Eisenman, 1991, p. 460). The lack of support was demonstrated in a national study which found that only $6 \%$ of institutions have participation and involvement of administrators in the assessment process (Peterson \& Einarson, 2001). Another study found that lack of administrative 
support was a barrier to assessment implementation for Extension faculty (ChapmanNovakofski et al., 1997).

Another difficulty that faculty have with assessment relates to the lack of sharing the results (Palomba, 1997). They fear that the assessment information they provide may not even be used at all (Palomba \& Banta, 1999). Researchers have found that many times assessment results regarding outcomes "only collect dust" even though the information can successfully contribute to accountability and improvement efforts (Jacobi et al., 1987, p. 10). Jacobi (1987) outlined four major obstacles to using assessment results which included inadequate determination of the purpose of the assessment from the start; technical barriers such as ineffective methodology, instruments, and analysis; political barriers; and if assessment is implemented solely to determine the "best" outcomes for the institution.

Faculty also resist when assessment findings, not assessment efforts, are used for tenure, promotion or salary decisions (Palomba \& Banta, 1999). Often, faculty avoid assessing their own programs in fear of possible punitive measures (Caffarella, 1994). This was also supported by Jacobi and Associates (1987) who found that faculty are resistant because they are afraid of negative evaluations. Faculty resistance can easily be overcome through constant communication about the differences between teaching evaluations and outcomes assessment.

Resistance to assessment also occurs when faculty believe that assessment is primarily used for external audiences and not for program improvement. If assessment were considered a fundamental component of the teaching process and not as a mandatory external factor, it would be seen as an enrichment of what faculty currently do 
(Eisenman, 1991). Williford (1997) found that this was an obstacle for Ohio University faculty since the initial reasons for doing assessment were external. The assessment study by Ory and Parker (1989) also reported that many assessment activities were due to mandates or external pressures.

Often, faculty fear that assessment for accountability purposes could result in a violation of their academic freedom (Eisenman, 1991) through an invasion into their current curriculum design and delivery (Brakke \& Brown, 2002). Some faculty feel that assessment is just a fad (Eisenman, 1991) and that the process really does not fully encompass the entire educational process (Jacobi et al., 1987). Select faculty also have difficulty in demonstrating that the program outcomes are linked to the activities of the educational program (Caffarella, 1994) which can serve as a barrier to assessment implementation. A number of faculty feel that assessment is too much work and too difficult since it really makes no difference anyway (Eisenman, 1991). A study of 1,393 institutions revealed few institutions reporting evidence that their assessment efforts actually produced impacts on students, faculty or external constituencies (Peterson \& Einarson, 2001).

Challenges to implementation also relate to the complexities of the assessment process itself. Faculty have difficulty in understanding and using the process due to its terminology and complex procedures (Gray, 1997). Ohio University faculty encountered a similar barrier to using assessment since they felt that there was a "lack of common language between administrators and faculty" (Williford, 1997, p.55). Evidence of this was found in a study that indicated that a major issue with assessment at large, research institutions was that there was "considerable confusion, and sometimes debate, over the 
term 'assessment activities' " (Ory \& Parker, 1989, p. 380). They also noted that many assessment efforts go unnoticed due to ambiguity and misunderstandings about assessment.

Barriers to implementing assessment exist with regard to the selection of assessment measures. There is uncertainty about the validity and reliability of individual assessment instruments (Banta, 1997). Faculty question the results and usually do not support organizational decisions based on low quality instruments (Palomba \& Banta, 1999). In support of this claim, one study demonstrated that "measurement issues/validity of results of assessment" were a critical problem with assessment (Muffo, 1992, p. 71). Using multiple measures helps compensate for the limitations of single assessment instruments.

Finally, the lack of involvement of students is also seen as a challenge in assessment implementation. The process should be seen as an "activity done with and for students, rather than to them" (Palomba \& Banta, 1999, p. 71). Students should be involved in assessment by serving on committees, articulating learning goals, and evaluating assessment instruments (Palomba \& Banta, 1999). One study found that student cooperation with assessment was considered a major concern by faculty (Muffo, 1992). In another study, when Extension faculty were asked about potential barriers to using evaluation, they reported that program participants were resistant to completing evaluation measures and written evaluations were difficult for participants to complete due to literacy issues and time constraints (Chapman-Novakofski et al., 1997). 


\section{Benefits of Implementing Assessment}

Although there are numerous challenges associated with the implementation of assessment, a multitude benefits exist as well. The assessment process results in increased clarity of the mission which contributes to an overall sense of shared purpose among administration and faculty as well as students (Banta, 1993a).

The first step in the assessment process, which is developing intended learning outcomes, results in a variety of benefits. One advantage is that the outcomes themselves become the basis of the assessment process for courses, programs, and the institution (Huba \& Freed, 2000). This step in the assessment process actually allows the outcomes to be used as a barometer to determine if the courses achieved what they were designed to achieve. Since outcomes should be designed by a team of faculty and administrators, the attainment of course outcomes should lead to the attainment of outcomes at the program level and eventually the institutional level. The result is the fulfillment of the institution's mission through enhancing the effectiveness of programs (Huba \& Freed, 2000). Assessment can help illuminate how educational programs are working and if they are contributing to learner growth (Palomba \& Banta, 1999).

Also, the intended learning outcomes inform the learners about what the faculty intentions are (Huba \& Freed, 2000) regarding what they should know and be able to do as a result of educational experiences. The learners benefit by being more knowledgeable about what there is to gain from their experiences as well as a sense of direction for their learning (Huba \& Freed, 2000). The faculty intentions, in the form of outcomes, should be communicated in catalog statements, syllabi, and other relevant materials (Huba \& Freed, 2000). 
Since intended learning outcomes encompass an array of assessment methods, the students' "diverse talents and ways of knowing" will be respected (Banta et al., 1996, p. 348). If assessment efforts are implemented effectively, students should also have enhanced contact and cooperation with other students as well as faculty (Banta et al., 1996). This increase in contact with faculty should also result in continuous feedback that identifies how well students are doing and which areas need improvement (Huba \& Freed, 2000).

The development of learning outcomes is also beneficial to the implementation process since they provide the direction for all learning activities (Huba \& Freed, 2000) which in turn allows faculty to gather evidence about their own teaching and their students' learning (Banta, 2002). With specific outcomes in mind, the planning of each lesson of the course is guided by the predetermined expectations of the learners. Instead of simply determining what material to cover, the focus shifts to the experiences that learners must have to achieve the outcomes (Huba \& Freed, 2000). These assessment efforts often result in changes in classroom activities and assignments in order to better promote student learning (Banta et al., 1996). Faculty and students can immediately benefit from these changes since faculty can more quickly identify learning deficits due to their increased clarity of goals.

When these classroom adjustments are not sufficient, improvements in curricula may be necessary for improving student learning (Banta et al., 1996). Using the results of assessment to make decisions about changes in the curricula is a vital benefit of the process. Examining the results enables faculty to determine if the curriculum makes sense and if students develop the knowledge and skills intended (Palomba \& Banta, 
1999). The curriculum "can be transformed into a unified, coherent set of learning experiences aimed at the cultivation of the explicitly stated learning outcomes" (Eisenman, 1991, p. 462). This results in faculty keeping current regarding the subject matter and the needs of students (Banta et al., 1996). In addition, assessment also results in improvements in the design and implementation of future assessments of student learning (Banta et al., 1996).

Benefits also arise in the assessment implementation process when the institutional environment is supportive. When there are knowledgeable and effective leaders from the top down involved in a well-thought out series of assessment activities, faculty are more motivated to participate (Banta, 2002). The fact that the assessment process is an ongoing mechanism and not simply a fad also serves as an influence for faculty to implement assessment. The development of institution-wide assessment requirements often foster support for the process (Palomba, 2002). The simple action of requiring faculty to document their use of assessment and its results serves as a positive influence in implementation.

Benefits of implementing assessment are also evident when administration is supportive through providing assessment resources for faculty. Oftentimes, administration will provide the necessary resources for faculty to study assessment through retreats, workshops, and conferences (Palomba \& Banta, 1999). It is necessary that faculty receive ongoing assessment training to remain motivated (Angelo, 2002). A study by Peterson and Augustine (2000) found that the extent of assessment training offered to faculty, staff, and administrators influenced their use of assessment results in making decisions. 
Another benefit of participating in assessment is access to resources provided by administration such as assessment manuals, newsletters, and publications developed on and off-campus. In addition to assistance related to increasing faculty skills, resources are also necessary with regard to the secretarial support (Palomba \& Banta, 1999) necessary to the assessment process.

Once faculty are trained in assessment, they benefit from implementation through their new roles and responsibilities. These new faculty roles require increased interaction with other faculty (Palomba \& Banta, 1999). With their collaborative participation in developing outcomes, creating assessment plans, making recommendations, and serving on committees (Palomba \& Banta, 1999), faculty benefit from the enhanced communication that occurs with faculty outside their discipline and with administration.

Another reward of participating in assessment involves receiving release time to participate in major assessment projects (Palomba \& Banta, 1999). As faculty increase their participation, additional opportunities arise with regard to sharing the information with the educational community. Faculty can communicate their assessment efforts and findings by writing newsletters, presenting posters, and publishing articles (Palomba \& Banta, 1999). Of course, this type of scholarly work can result in faculty recognition which can be beneficial for the promotion and tenure process (Palomba \& Banta, 1999). In order for this to be beneficial, assessment has to be accepted and recognized as a scholarly activity since some faculty feel that assessment is often "not recognized by their peers or rewarded in the promotion and tenure process" (Banta, 2002, p. 287).

Oftentimes, implementation of assessment can result in additional funding being made available to particular projects. Some institutions offer small grants and stipends to 
faculty who are participating in large assessment projects (Palomba \& Banta, 1999). There is evidence that the additional funding devoted to assessment projects proves to be beneficial in the success of assessment (Palomba \& Banta, 1999). On the other hand, Angelo (2002) claimed that paying faculty to participate in assessment is a risky strategy that may result in them disengaging from the process when the funding ends. $\mathrm{He}$ explained that providing assessment materials and training was a better use of funding than stipends.

The organization benefits from assessment efforts by increasing its capacity to deal with issues such as government regulation, intensified competition, program delivery transformations, and clientele diversity (Palomba \& Banta, 1999). By implementing and using assessment, faculty and administrators can clearly demonstrate the benefits of their courses and programs. The assessment information can also be used to mobilize support to persuade stakeholders (Gray, 2002) which can lead to future funding. In general, higher education has a lot to gain from being involved in assessment efforts but a lot to lose if not able to explain the value of its programs (Brakke \& Brown, 2002).

In conclusion, the review of the assessment literature is based on research findings by recognized assessment scholars. The assessment literature strongly confirms how accountability as well as the need for improvement within higher education have driven assessment efforts. In addition to the American Association of Higher Education principles of good practice for assessing student learning, there have been identified essential assessment elements which include formulating learning outcomes; creating experiences leading to outcomes; developing assessment measures; and discussing the results of assessment (Huba \& Freed, 2000). Based on the research findings, the 
implementation of these strategies is impeded by a variety of barriers as well as encouraged by recognized benefits that assessment can result in. Although there is extensive literature on the most effective approaches to implementing assessment, there is a lack of abundant research studies related to how faculty are actually utilizing assessment. "What we have not yet determined systematically is how deeply assessment has penetrated...Has assessment endured beyond the experimentation and early adoption phases?" (Magruder, McManis, \& Young, 1997, p. 80). In addition, a very limited number of studies have been conducted regarding assessment implementation within Cooperative Extension.

\section{Definition of Key Terms and Concepts}

1. Assessment- process that gathers data from various sources to determine how students' knowledge, attitudes, and behaviors have changed as a result of their experiences (Huba \& Freed, 2000).

2. Utilization of assessment- extent to which faculty are formulating statements of intended learning outcomes; selecting data gathering measures; designing effective learning experiences leading to the outcomes; and discussing and using assessment results (Huba \& Freed, 2000). The extent of utilization is based on the number of self-reported agreements with statements in each of the four assessment categories.

3. Class level- assessment level that includes assessing learners' achievement of outcomes for single, one-time classes as well as classes that occur in a series over time in Extension 
4. Program level- assessment level that includes assessing learners' achievement of statewide outcomes in the disciplines of agriculture, youth development, and family and consumer sciences.

5. Institutional level- assessment level that includes assessing learners' achievement of institutional outcomes related to the overall mission.

6. Benefits of implementing assessment- advantages that encourage faculty participation in assessment efforts.

7. Challenges of implementing assessment- barriers that interfere with faculty participation in assessment efforts.

8. Discipline- Cooperative Extension program areas of agriculture, youth development, and family and consumer sciences.

9. Rank- levels of faculty which include full professor-principal agent, associate professor-senior agent, assistant professor-agent.

10. Assessment methods- Strategies used to measure the attainment of intended learning outcomes. Methods include direct methods such as examinations, demonstrations, and portfolios and indirect methods such as questionnaires, interviews, and focus groups (Palomba \& Banta, 1999). 


\section{CHAPTER 3}

Method

This chapter describes the research procedures used in the examination of assessment practices of University of Maryland Cooperative Extension (MCE) faculty by exploring the degree of faculty utilization of assessment including the use of assessment results as well as the differences in utilization among faculty of various ranks and disciplines. The study identified what faculty believed were the benefits and barriers of implementing assessment. Included in this chapter are the following sections:

population, research design, pilot study, data collection, and data analysis.

\section{Population}

The population for the study was Cooperative Extension faculty of the University of Maryland, College Park. This higher education institution is classified as a Doctoral/Research University- Extensive in the Carnegie Classification System (Carnegie Foundation, 2003). The Associate Dean of Maryland Cooperative Extension approved the identification of the name of the institution in this study as long as the anonymity of individual faculty responses was guaranteed. The 175 faculty were located on campus and off campus at educational centers located in the 23 Maryland counties, Baltimore City, and at four research centers. They taught full-time and had the following ranks: Assistant Professor- Agent; Associate Professor- Senior Agent; or Professor- Principal Agent. The faculty also differed by discipline which included the following: family and consumer sciences; agriculture and natural resources; and 4-H and youth development.

Since this was a small population of 175 individuals, all faculty were invited to participate in the study (Suskie, 1996). A list of addresses of all full-time Extension 
faculty was obtained through the 2003 University of Maryland Cooperative Extension staff and faculty directory. Prior to contacting faculty by mail, approval for conducting the study was obtained from the Associate Dean of the College of Agriculture and Natural Resources who is also the Associate Director of Maryland Cooperative Extension. The permission letter is included in Appendix A.

\section{Research Design}

A quantitative research approach was used due to the nature of the research questions described in Chapter 1. These quantitative procedures guided the study through a survey design. Survey research was the type of quantitative approach that was used to fully examine the current state (Gay \& Airasian, 2000) of assessment efforts within Extension. It was used as a tool for discovering what was occurring at present with faculty (Tuckman, 1999) through examining specific characteristics (Fraenkel \& Wallen, 2000). The survey was designed to describe, explore, and explain (Suskie, 1996) the preferences, attitudes, practices, concerns or interests (Gay \& Airasian, 2000) of faculty with regard to assessment practices.

An advantage of using this method was that the information could be transformed into quantitative data by using rating scales or frequencies (Tuckman, 1999). This allowed for the collection and analysis of numerical data. Another rationale for using surveys in this study was that an abundance of data could be collected by a large number of faculty (Fraenkel \& Wallen, 2000). The survey design was chosen so that the data could be used for a wide-range of decision-making purposes (Suskie, 1996) about faculty needs in the area of assessment. The survey allowed for the most standardization and 
required the least training to administer compared to other descriptive data collection methods (Gay \& Airasian, 2000).

A limitation of this method was that the data were self-reported since the researcher asked participants about their behaviors rather than observing their behaviors (Tuckman, 1999). Another disadvantage with the survey was that participants had to cooperate by completing and returning the surveys (Fraenkel \& Wallen, 2000; Gay \& Airasian, 2000). Also, participants had to know what they felt and thought in order to report it in the survey (Tuckman, 1999). The validity could have been an issue since participants may have wanted to show themselves in a good light; tell the researcher what they thought he or she wanted to hear; and may have not really known the answers to the questions (Tuckman, 1999).

In order to overcome some of the limitations of the survey design, several qualitative components were added. In addition to open-ended questions imbedded in the survey, participants were asked to provide examples of learning outcomes and copies of assessment instruments.

A cover letter (see Appendix B) and the Survey of Assessment Utilization By Extension Faculty (see Appendix C) were developed by the researcher after a comprehensive review of the assessment literature. Content validity was established since the development of each item on the survey was directed by the assessment literature discussed in Chapter 2, including Huba and Freed's (2000) essential elements of assessment as well as the American Association of Higher Education's principles of good practice for assessing student learning (1992). 
The items on the survey were developed to elicit responses which provided information on faculty utilization of assessment practices including the development of learning outcomes, data gathering measures, experiences to achieve the outcomes, and uses of assessment results. Sections regarding the benefits and challenges of implementation of assessment were included. The survey combined multiple choice questions, Likert rating scales, and open-ended questions (Suskie, 1996). Completion of the survey was intended to take research participants approximately 15 minutes. In addition to completing the survey, study participants were asked to supply sample documents which included two data gathering instruments such as a tests or surveys that they use with their students.

\section{Pilot Study}

The research procedures for the study of the "Utilization of Assessment by Maryland Cooperative Extension Faculty" were pilot tested at West Virginia University to determine what modifications needed to be made. The pilot study served as a "smallscale trial of the proposed procedures" in order to identify any problems that needed solved prior to implementation of the actual study (Fraenkel \& Wallen, 2000, p. 618). Upon approval by West Virginia University's Institutional Review Board for the protection of human subjects, the pilot study took place with West Virginia University Extension faculty.

The participants included six tenure-track field faculty of West Virginia University Extension. Assurances were made for voluntary participation by contacting the six participants by telephone to briefly describe the pilot study. A standard protocol was used to explain the survey and to inform them that all of their answers would remain 
confidential and not be associated with their names. The faculty members were then asked to participate and if agreeable, the pilot study packet was sent by mail to each participant.

The packet included the pilot cover letter, the study cover letter, the seven-page survey, and a postage-paid envelope for returning the documents. The pilot cover letter outlined the instructions for participating in the pilot study (see Appendix D). The letter included information about completing the survey, making notes regarding any problems that might be uncovered, and scheduling a time to do an interview following the completion of the survey. The study cover letter outlined the purpose of the study, details for completing and returning the survey, and information about assurances of anonymity (see Appendix B). The cover letter also described two additional documents that each participant should enclose when they return their completed survey. These documents included a sample of intended learning outcomes for one class and a data gathering measure such as a test or survey used for one class. The timeline for returning these documents along with the survey (see Appendix C) was within 10 days.

Participants for this study were selected purposefully (Glesne, 1999). Maximal variation sampling was the specific participant selection strategy that was used to reveal the range of variation and differentiation across faculty discipline (Flick, 1998). The variation involved the selection of two faculty from each of the three disciplines of family and consumer sciences; agriculture and natural resources; and 4-H and youth development. Participants not only differed in discipline, but also ranged in gender, rank, and age. 
This pilot study involved the administration of a survey to six Extension faculty members in order to obtain necessary information for improving the instrument. Each of the six selected faculty members was interviewed following completion of the survey. The type of interviewing that was conducted was structured since there was a set of specified questions that were asked of each participant (Glesne, 1999). Each question was developed to gather information about the participants' perceptions with regard to the cover letter and survey. Participants were asked about items such as the cover letter's clarity, ease of reading, and return instructions. Questions about the survey included inquiries regarding the clarity, difficulty level, organization, length, unfamiliar terms, and suggestions for improvement. A copy of the exact interview questions can be found in Appendix E.

Interviewing each pilot study participant allowed for the quick obtainment of large amounts of data. One weakness of the method was the fact that the results were highly dependent upon the honesty of the participants (Marshall \& Rossman, 1995). The details of this pilot study were reviewed by the College of Human Resources and Education at West Virginia University and approved for exemption under the Human Subjects Policies.

A number of strategies were utilized for analyzing the interview data. First, there was a simple scanning of the data for relationships and categories. Comparisons were made for the identification of concepts that consistently appeared among participants (Merriam, 1988). Coding comments were written on the interview notes to determine what major ideas were emerging (Strauss \& Corbin, 1990). These concepts were sorted 
and clustered into themes. Finally, it was determined how these categories were related to each other and how they could be integrated into the dissertation research.

A number of major concepts emerged from the interview data obtained from the six West Virginia University Extension faculty. The interview was divided into two sections, which included a cover letter section and a survey section. The interview data from the cover letter section indicated that the most prevalent overall issue was with the request for the sample documents of a data gathering measure and a copy of intended learning outcomes. Although each participant returned his or her survey to the researcher, not one enclosed a copy of intended learning outcomes designed for a class. When asked about this issue, all six participants claimed that they do not formally write down their intended learning outcomes for each class. One reason that was given was that they are not required to do syllabi or any other formal documents for their classes. In general, participants felt that writing intended learning outcomes prior to teaching a class was an essential issue in assessment but that it was not occurring at this time among faculty.

Of the six participants, only two of them included samples of data gathering measures with the return of their completed surveys. When asked in the interview about this topic, the response was that faculty are not required to do anything beyond a standard end-of-class reaction form that measures their own performance. According to three participants, it is strictly optional if faculty want to design assessment tools to examine the impact of their classes.

Four pilot participants felt that these requested documents might affect the response rate. The suggestion was made that enclosing the documents should be an 
option for a number of reasons. For instance, some people may think that since administration supports this project that those documents may be evaluated for quality by administration. Another issue was that the development of tests and surveys is unique information that faculty may not want to share. Also, some participants may feel inadequate and not fill out the survey at all if they think they have to enclose documents that they do not have.

As for the format of the cover letter, the most frequently mentioned issue was about its length. Four participants claimed that the cover letter contained too much text and needed to be shortened so that participants would read it thoroughly. Another participant stated that the number of words should be decreased and that the format should be revised to include bulleted items to make it easier to read.

Responses to the first interview question about the cover letter were similar among participants. All of the pilot study participants felt that the purpose of the research was clearly stated in the cover letter. The only suggestion for improvement was to place the purpose at the very beginning of the letter. Participants would then know immediately why they received the letter and survey.

As for the responses to the question about the benefits of the study, five of the participants reported that the benefits were very clear. One pilot participant was uneasy about the statements regarding administration's support of the study. It was suggested that the wording be changed so that it would be clear that it is an independent research project that is not sanctioned by administration. It was proposed that the emphasis be placed on the fact that individual responses will not be shared but that the overall results will be communicated for organizational improvement. 
Three participants suggested that the instructions for returning the documents should be easier to spot on the cover letter. One recommendation was to place bullets beside the directions that the study participant needed to follow so that he or she could quickly refer to them. This was suggested to enhance participants' motivation to complete the process. One participant stated his motivation was increased by the phone contact by the researcher prior to receiving the survey. Another claimed that "nothing in the world motivates me to do a survey."

One-half of the pilot participants recommended that the date for returning the documents should stand out in either bold or underlined in the letter. One participant was extremely concerned with the statement about participants not being required to respond to every item on the survey although it was an IRB requirement. A recommendation was made to maintain the concept with different wording in an attempt to improve the response rate.

A number of commonalities existed among pilot participants' answers to the interview questions about the survey. The interview question that asked participants about any unfamiliar terms resulted in a number of comments. Two participants felt that the language used in some sections was not highly applicable to Extension faculty. It was suggested that minor revisions should be made to the overall tone to make it more Extension-related. In addition, three pilot participants claimed that there was a need to reword or clarify several titles such as program level, effective educational experiences, and data gathering measures since the terms mean different things to different people.

When asked if the organization of the survey made sense, three participants had positive responses about the structure of the survey. One participant criticized the design 
of the rating scales since the design itself might result in response bias since the positive response is listed first on each item of the survey. The comment was that it leads participants since they would not have to read beyond the "strongly agree" rating. Two of the participants suggested that when a respondent answers yes to certain items that he or she should be referred to the next question in the survey that they need to answer.

In relation to the interview question about whether any of the questions were difficult to answer, a few concerns were voiced about specific assessment terms. These issues dealt with the difficulty in reading and understanding the items in the first two sections of the survey related to the assessment benefits and challenges. It was proposed that shorter phrases be used rather than complete sentences to describe the benefits and challenges.

The responses from the final interview question that asked for additional suggestions varied among participants. One participant recommended that the several of the survey items needed to be more personalized. Instead of asking respondents to describe the assessment benefits that exist, it was suggested to change it to what benefits "I" experience. Using the word "I believe or fear" instead of "faculty believe or fear" allows the respondent to answer for himself instead of choosing an answer that would apply to all faculty.

A suggestion that was made by one pilot study participant was to add a few additional demographic questions. She felt that educational level and educational background are two demographics that should be asked. Following the demographic questions, it was suggested that a reminder be placed at end of the survey regarding the enclosure of all of the requested documents. 
Overall, five of the participants reported that the survey was lengthy, and if it were condensed, better response rates might occur. The comments included the following: "Make it more brief."; "Possibly make it a little shorter."; and "Cut it down a bit." In order to attempt to improve the response rate, one pilot study participant recommended offering incentives to those who complete the survey. When asked how long the survey took to complete, the participants' answers ranged from 10 minutes to 20 minutes.

Based on the results of the pilot study, only one major change was made to the research plan itself. This adjustment involved eliminating the request for copies of intended learning outcomes from study participants. Instead of providing a sample, a survey item was designed to ask participants to write three examples of learning outcomes directly on the survey in an open-ended question. Other than the completed survey, actual study participants were required to enclose is a copy of one of their own assessment measures and one from another professional or institution that they used for measuring outcomes.

A number of minor changes were made to the structure and wording of the cover letter. Modifications were made to the cover letter so that its length was slightly shortened. The important components of the letter, such as instructions for returning the documents, were emphasized through bold and bulleted text. The ordering of several sentences was changed including the placement of the purpose of the study as the first sentence. A sentence was also added that addressed the fact that the survey responses and the documents would not be shared. The assessment definition was reworded 
slightly to be more Extension-related. See Appendix F for the revised, final version of the cover letter.

The pilot study resulted in a variety of alterations to the survey. There were some minor changes to the overall tone of the survey through insertions of the word "Extension" in appropriate places. One such place was in the definition of assessment. The entire survey was also revised to make it more personal so that participants would be asked to respond to questions from their own perspectives. The word "faculty" was replaced with either "I" or "my" to make the items more individualized.

Several words were changed from the expressions used in the literature to words that were more recognizable by Extension faculty. Titles of sections changed from "Intended Learning Outcomes" to "Developing Learning Outcomes", "Data Gathering Measures" to "Designing Assessment Measures", and "Effective Educational Experiences" to "Creating Extension Education Experiences."

Changes were also made to the first two sections of the survey that addressed assessment benefits and challenges. These items were reworded from complete sentences to phrases that began with verbs. Rewording was also done to make certain that there was consistency throughout the document with regard to certain words such as "program level" and "program area".

Since there were only 79 questions and space allowed, one additional demographic question was added. This question asked participants to identify their highest level of educational attainment. A final reminder was placed at the end of the survey to prompt participants to enclose their assessment measure with the completed survey. See Appendix G for the revised, final version of the survey. 
The pilot testing helped establish content validity since pilot participants thoroughly examined the completeness of the survey (Gay \& Airasian, 2000). The survey also had content validity since the situations it measured are representative of situations in the population (Tuckman, 1999). Content validity was strengthened since there was a systematic identification of credible assessment literature which was used to develop the measure (O’Sullivan \& Rassel, 1995). Each item within each section of the survey was supported by literature written by recognized assessment scholars.

To make certain that the survey measures what it was supposed to measure, validity was enhanced through triangulation (Suskie, 1996). The study used multiple sources of data such as the quantitative survey data and the qualitative information found in the requested sample documents provided by participants.

Reliability or consistency of responses was established through the survey's clear directions, logical order of the questions, closed-ended questions, and simple item formats (Suskie, 1996). Reliability was enhanced through conducting of the pilot study and its close examination of survey items. The feedback from pilot study participants should led to clarification of certain parts of the survey, which improved the reliability.

The trustworthiness of the data was ensured since triangulation occurred with the data from the survey and sample documents, all of which will be analyzed either quantitatively or qualitatively. The researcher attempted to recognize and monitor her subjectivity (Peshkin, 1988) throughout the process, which contributed to more trustworthy research (Glesne, 1999).

The data needed to answer the research questions described in Chapter 1 were gathered through a written survey with 78 identical questions (Fraenkel \& Wallen, 2000) 
The final version of the survey contained six sections related to assessment practices and one section devoted to demographics. There were four questions provided for research participants to share more qualitative information.

\section{Data Collection}

The final versions of the cover letter (Appendix F) and the survey (Appendix G) were administered, by mail on April 1, 2003, to all 175 University of Maryland Cooperative Extension faculty on and off campus. In an attempt to ensure a high response rate, each cover letter was personally addressed to each faculty member. The cover letter described the nature of the study, provided the necessary definition of terms, and explained the intent of the survey. The survey and requested documents were to be returned within two weeks in the postage-paid envelope. An executive summary of the survey results was offered to those who participated.

Each survey was assigned a number that corresponded with a specific faculty member in order to allow the researcher to enhance the response rate through following up with non-respondents. The participant code information was kept confidential during the entire research study. A follow-up reminder letter was sent to non-respondents on April 18, 2003. Two weeks later, another cover letter and survey were sent to the remaining non-respondents.

\section{Data Analysis}

The quantitative data were analyzed using the Statistical Package for the Social Sciences (SPSS) 11.0 for Windows. Data from survey items 31 through 58 (see Appendix G) addressed the first research question, “To what degree are Cooperative Extension faculty utilizing assessment at the class, program, and institutional levels?" 
Each item was designed as a four-point Likert scale so that respondents could identify the frequency of specific assessment practices. First, these data addressed the effective utilization of assessment and were analyzed by descriptive statistics. These statistics determined if and how often faculty were formulating intended learning outcomes, developing data gathering measures, and creating effective educational experiences. Questions within each of these three survey sections addressed utilization at the class, program, and institutional level. Frequencies of responses and means were determined. In addition to the quantitative analysis for the first research question, item 38 on the survey (see Appendix G) provided qualitative data related to intended learning outcomes at the class level. The examples of the outcomes were studied to determine if faculty were focused on student-centered aspects of learning. These data were analyzed for evidence of use of learner outcomes in the cognitive, affective, and psychomotor domains. The number of learner outcomes in each category was then totaled.

A qualitative content analysis was conducted with regard to the data gathering measures that were requested from participants in survey items 50 and 52 (see Appendix G). This content analysis involved identifying, coding, and categorizing patterns in the data (Patton, 1990). The type of content analysis that was conducted was qualitative or nonfrequency (Fraenkel \& Wallen, 2000) since it was determined whether the essential assessment elements outlined in the literature were utilized in the document samples. The samples of the data gathering instruments were examined to determine if faculty were utilizing direct or indirect assessments and to identify what domains of student learning faculty were using. This qualitative analysis of the outcome examples and the data gathering measures helped to enhance the validity of the survey data that addressed 
the first research question, “To what degree are Cooperative Extension faculty utilizing assessment at the class, program, and institutional levels?"

The data that addressed research questions two, three, and four were quantitatively analyzed using descriptive statistics such as means and frequencies. Research question two, "What do faculty perceive to be the benefits of implementing assessment?", was addressed through survey items one through 15 (see Appendix G). Survey items 16 through 30 examined the third research question, "What do faculty perceive to be the challenges of implementing assessment?" The fourth research question, "How do faculty use the results of assessment to make improvements?" was addressed through survey items 59 through 71 (see Appendix G).

The fifth research question, "Is there a statistically significant difference among faculty across disciplines (agriculture, youth development, and family and consumer sciences) regarding their utilization of assessment?" involved inferential statistics. The independent variable was the discipline from survey item 73 and the dependent variables were each item in survey Sections C, D, E, and F, which addressed the four essential elements of effective utilization of assessment. A multivariate analysis of variance (MANOVA) was used to determine whether or not the variable means differed significantly across the three disciplines (Cronk, 1999). The MANOVA was used since there were multiple dependent variables (Coughlin \& Pagano, 1997). Three MANOVA's were computed on the data in survey Section $\mathrm{C}$ which focused on developing learning outcomes. One MANOVA was calculated on the data in each of the following survey sections: Section D-Designing assessment measures, Section E- Creating extension education experiences, and Section F- Using assessment results. These multivariate tests 
examined all dependent variables at once (Cronk, 1999). If the results were statistically significant, then an analysis of variance (ANOVA) was computed for each individual dependent variable.

The sixth research question, "Is there a statistically significant difference among faculty across different ranks (full professor-principal agent, associate professor-senior agent, assistant professor-agent) regarding their utilization of assessment?" also involves inferential statistics. The independent variable was rank from survey item number 75 and the dependent variable was each survey item in the four sections addressing the essential elements of effective utilization of assessment. MANOVA's were calculated as in the fifth research question to determine whether or not the variable means differed significantly across the three ranks (Cronk, 1999).

In summary, this chapter included the methods that were used to carry out the study. First, the sample was described as the entire population of 175 Maryland Cooperative Extension faculty. The research design was depicted as quantitative in nature by utilizing the survey approach. A number of qualitative components complemented the design and ensured trustworthiness. A pilot study with Extension faculty in another state served to enhance validity. Finally, the data analysis utilized descriptive and inferential statistics as well as qualitative content analysis.

Chapter 4 presents the results of this assessment research study. It also describes the population and sample as well as the demographics of the faculty respondents in the study. The emphasis of the chapter is on the statistical analyses of the data for the six research questions. Chapter 5 serves as the conclusion to the study with recommendations for future research and practice. 


\section{CHAPTER 4}

Results

The results of the research study, including statistical analyses of the data, are presented in Chapter 4. The chapter begins by outlining the population and sample and includes a discussion of the study's response rate. Next, the demographic characteristics of the research participants are presented. Finally, the quantitative and qualitative data are described for the six research questions.

This study explored the degree of faculty utilization of assessment practices at the class, program, and institutional levels within the University of Maryland Cooperative Extension (MCE). The research explored the differences in assessment utilization among faculty of various ranks and disciplines. This inquiry also identified what faculty believed were the benefits and challenges of implementing assessment. Finally, how faculty used the results of assessment to make improvements was examined.

\section{Population and Sample}

Cooperative Extension faculty of the University of Maryland, College Park, served as the population for this study. This institution is classified as a Doctoral/Research University-Extensive in the Carnegie Classification System (Carnegie Foundation, 2003). These faculty were located on campus and off campus at educational centers located in the 23 Maryland counties, Baltimore City, and at four research centers. The 175 Extension faculty at the University of Maryland taught full-time and had the following ranks: Assistant Professor- Agent; Associate Professor- Senior Agent; or Professor- Principal Agent. The faculty also differed by discipline which included the 
following: family and consumer sciences; agriculture and natural resources; and 4-H and youth development.

The 78-item survey was mailed, along with a personalized cover letter, to all 175 faculty members. The first mailing resulted in the return of a total of 82 surveys by the two-week deadline. A reminder letter was then sent to the remaining 93 nonrespondents to encourage survey completion within two weeks. Another 18 surveys were returned by the second deadline. As a last effort to increase the response rate, the survey was mailed to the remaining nonrespondents. This resulted in an additional six surveys being returned on the third round. One hundred and six surveys were returned for a response rate of $61 \%$. From this total, eight were not completed which left 98 surveys with a useable response rate of $56 \%$.

The reasons varied as to why faculty returned the surveys uncompleted. One respondent stated that he did not do assessments, while another claimed that she did not participate in those types of activities. Another respondent sent back the survey with the statement "I don't have time for this!" written at the top. Others no longer had positions with Maryland Cooperative Extension appointments.

\section{Demographic Data}

A diverse group of 98 faculty participated in the study and varied by gender, main programmatic focus, campus location, current rank, and highest level of educational attainment. Fifty-two males (53\%) and 46 females (47\%) participated in the study. As for their main programmatic focus or discipline, $59 \%$ of the faculty taught in the field of agriculture with the remainder in the other two disciplines (see Table 1). 
Table 1

Main Programmatic Focus of Faculty

\begin{tabular}{lcc}
\hline \multicolumn{1}{c}{ Programmatic Focus } & $N$ & $\%$ \\
\hline Agriculture \& Natural Resources & 58 & 59 \\
Family \& Consumer Sciences & 22 & 23 \\
4-H \& Youth Development & 16 & 16 \\
Missing Data & 2 & 2 \\
Total & 98 & 100 \\
\hline
\end{tabular}

The next demographic item on the survey was related to the location of where the faculty were based. Field faculty, teaching in individual counties, made up the largest group of respondents (53\%) with 52 faculty members. There were 14 regional faculty (14\%) from the four research centers who participated in the study. Of the 98 respondents, 32 of them (33\%) were campus-based faculty.

The faculty also differed by professorial rank. Forty-eight percent of the respondents were associate professors/senior agents. Assistant professors/agents made up $24 \%$ of the sample while full professors/principal agents made up another $24 \%$ of the faculty. (see Table 2). 
Table 2

Professorial Rank of Faculty

\begin{tabular}{lcc}
\hline \multicolumn{1}{c}{ Programmatic Focus } & $N$ & $\%$ \\
\hline Full Professors/Principal agents & 23 & 24 \\
Associate Professors/Senior Agents & 47 & 48 \\
Assistant Professors/Agents & 24 & 24 \\
Missing Data & 4 & 4 \\
Total & 98 & 100 \\
\hline
\end{tabular}

The final demographic item addressed faculty educational attainment. The greatest representation of study participants included the 63 respondents (64\%) with Masters degrees. There were 33 respondents (34\%) with doctoral degrees and one (1\%) with a bachelors degree.

\section{Research Questions}

The results of the research study are outlined for each of the six research questions. Descriptive statistics such as means and frequencies were used to answer research questions one, two, three, and four. The survey items that addressed these research questions were mostly Likert scale questions. It was appropriate to calculate means for these questions since the number that was coded provided the direction of the average answer (Bozylinsky, 2001). For research questions five and six, multivariate analysis of variance and analysis of variance tests were calculated to examine the differences among groups. Tukey's HSD post-hoc tests were computed on the survey 
data for significant results. The $\alpha$ level was set at .05 for all of the inferential statistical analyses.

\section{Research Question One - Utilization of Assessment}

The first research question addressed the degree to which Maryland Cooperative Extension faculty were utilizing assessment. The items that linked to this research question were in Sections C, D, and E of the survey which included items 31-58 (see Appendix G). These survey sections focused on three of the four essential components of effective utilization outlined by Huba and Freed (2000) which included (1) developing learning outcomes at the class, program, and organizational levels; (2) designing assessment measures; and (3) creating effective educational experiences. The fourth component of effective assessment utilization included using the assessment results, and it was addressed in a separate research question.

The items were in a four-point Likert scale so that respondents could describe how often they carried out certain assessment-related tasks. The items included the following responses: the number four represented always; three represented often; two represented sometimes; and one represented never. The data from the items were analyzed using frequencies and means. Three of the items were qualitative in nature and required qualitative analysis of the data.

First element of effective assessment- Developing learning outcomes.

The first component of effective utilization of assessment is developing learning outcomes. This study examined learning outcomes at three levels including the class, program and organizational levels. 


\section{Class level outcomes}

The data indicated that faculty utilized a number of vital elements of developing class level outcomes. Respondents reported how frequently they developed class level outcomes according to specific assessment practices outlined in the literature. In general, one-quarter of the respondents indicated that they always linked class level outcomes to significant aspects of learning (see Table 3).

Forty-eight percent of the faculty specified that they always focused the outcomes on improving knowledge. This is in comparison to only $28 \%$ always focusing on modifications in behaviors; $23 \%$ always focusing on changes in attitudes and values; and $23 \%$ always focusing on improvements in critical thinking (see Table 3). These results were in similar alignment with the Peterson and Einarson (2001) study, which found that $34 \%$ of institutions were focusing on knowledge improvements.

With regard to class level outcomes being connected to the mission, vision, and values of the organization, the largest percentage of faculty (32\%) reported that they often did so. When asked if they clearly communicated class level outcomes to learners via a handout or a slide, $42 \%$ of faculty indicated that they often shared the outcomes using that method (see Table 3). 
Table 3

Research Question One: Development of Class Level Outcomes by Faculty

\begin{tabular}{|c|c|c|c|c|c|c|c|}
\hline \multirow[b]{2}{*}{ Class Level Outcomes } & \multirow[b]{2}{*}{$N$} & \multicolumn{4}{|c|}{ Frequency of Outcomes } & \multirow[b]{2}{*}{$M$} & \multirow[b]{2}{*}{$S D$} \\
\hline & & $\begin{array}{c}\text { Always } \\
\%\end{array}$ & $\begin{array}{c}\text { Often } \\
\%\end{array}$ & $\begin{array}{c}\text { Sometimes } \\
\%\end{array}$ & $\begin{array}{c}\text { Never } \\
\%\end{array}$ & & \\
\hline Linked to significant learning aspects & 91 & 25 & 53 & 20 & 2 & 3.01 & 0.74 \\
\hline Connected to mission & 94 & 30 & 32 & 31 & 7 & 2.84 & 0.94 \\
\hline Improved knowledge & 95 & 48 & 44 & 7 & 1 & 3.38 & 0.67 \\
\hline Enhanced critical thinking & 95 & 23 & 43 & 32 & 2 & 2.87 & 0.79 \\
\hline Changed attitudes/values & 93 & 23 & 47 & 28 & 2 & 2.90 & 0.77 \\
\hline Modified behavior & 95 & 28 & 45 & 25 & 2 & 2.98 & 0.79 \\
\hline Communicated to learners & 95 & 26 & 42 & 27 & 5 & 2.87 & 0.85 \\
\hline
\end{tabular}

Note. The item responses were made on a 4 -point Likert scale $(1=$ never, $4=$ always $)$. 
In addition to the quantitative data related to the class level outcomes, qualitative data were collected as well. One survey item asked respondents to reflect upon their class outcomes and write three examples. Forty-four faculty (45\%) in the study provided examples of their class level outcomes. After coding, grouping, and analyzing the 115 learning outcomes provided by study participants, it was apparent that 70 of the learning outcomes $(61 \%)$ were of the cognitive domain.

The cognitive learning outcomes were written at all six levels of Bloom's (1956) taxonomy. The largest proportion (36\%) of the outcomes were at the first level of cognitive learning which involved simple knowledge or recall of previously learned material. One example of this type of outcome was that learners could "recall the five components of proper hand-washing to prevent food-borne illness." Bloom's second level of cognitive learning was evident in 10 outcomes (14\%), which involved classifying, describing, and identifying information. An example that one respondent gave was that learners "will identify and classify high carbohydrate foods according their potential effect on blood glucose levels of diabetics.” There were 22 outcomes (31\%) that fit into the third cognitive level, which included the application and use of knowledge in concrete situations. One respondent presented an example that fit this category and it involved the learner applying the knowledge gained to "develop a budget, establish a record keeping system, and track revenue and expenses for two weeks."

The fourth level of Bloom's taxonomy was present in three outcomes (4\%). An example of analyzing and breaking material down was an outcome that required learners to "weigh the pros and cons of pest management to make the most appropriate decision." There were only three learning outcomes (4\%) written at the fifth level of the taxonomy. 
One respondent described how learners would synthesize and arrange knowledge to "diagnose the financial strengths of a particular business and make recommendations." Finally, there were seven outcomes (10\%) written at the sixth level of Bloom's taxonomy, which required learners to judge the value of the material. An example outcome required learners to "evaluate the money management techniques presented to determine how they could be utilized to strengthen a particular financial situation."

The qualitative analysis also indicated that faculty members were measuring learning in the psychomotor domain. There were 39 psychomotor outcomes $(34 \%)$ that related to changing specific behaviors among learners. One 4-H and youth development example was that the learner would "demonstrate safe and effective use of a physical challenge course." Another outcome was to "demonstrate the recommended uses of pesticides on crops." One other example was that the learner would "choose foods low in saturated fat during a supermarket tour."

Of the 115 total outcomes, only six respondents (5\%) utilized the affective domain of learning outcomes. One example was that the learners would feel "more able to provide interesting, safe food experiences for young children." Another participant stated that learners "would increase awareness of poultry disease and prevention."

In summary, the quantitative data gathered with regard to the focus of class level outcomes were congruent with the qualitative data provided via the outcome examples. For example, $48 \%$ of faculty indicated on the quantitative item that they always focused outcomes on knowledge improvements (see Table 3). This coincided with the $61 \%$ of faculty who provided outcomes written at the cognitive level. Another example was the $28 \%$ of faculty who claimed, in the quantitative item, that they focused outcomes on 
behavior modifications (see Table 3). Correspondingly, 34\% of participants provided outcome examples in the psychomotor domain. These results were in alignment with a previous study that found that psychomotor outcomes were less often assessed than cognitive outcomes (Ewell, 1983).

\section{Program level outcomes}

The next section of the survey asked faculty to report how frequently they developed and used certain program outcome practices outlined in the literature. Data analysis revealed that the largest percentage of faculty (54\%) often linked program outcomes to the mission, vision, and values (see Table 4). This finding indicated that faculty liked the mission to program level outcomes more often than class level outcomes.

The majority of faculty (56\%) indicated that they often achieved program level outcomes through delivering educational experiences in the form of classes. With regard to attaining program level outcomes by collaborating with other faculty within their program area, $50 \%$ of faculty reported that they often did so. When asked if the program outcomes were shared effectively with learners, $61 \%$ of faculty indicated that they only did so sometimes (see Table 4). This indicated that faculty shared program level outcomes with learners less often than class level outcomes. 
Table 4

Research Question One: Development and Use of Program Level Outcomes by Faculty

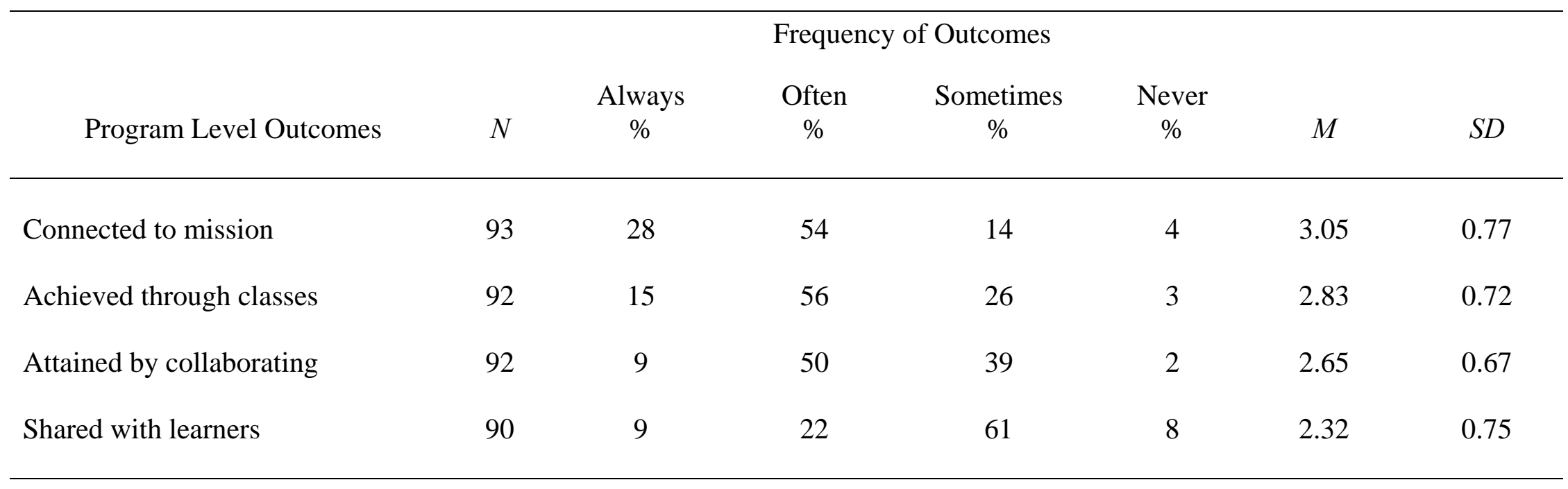

Note. The item responses were made on a 4 -point Likert scale $(1=$ never, $4=$ always $)$. 


\section{Organizational level outcomes}

The final outcome level of the survey asked respondents about their development and use of specific organizational outcome practices outlined in the literature. Data analysis revealed the largest percentage of faculty (42\%) often linked organizational outcomes to the mission, vision, and values (see Table 5). As for faculty sharing organizational outcomes with learners, stakeholders, and the public, the largest number of responses (57\%) was in the sometimes category (see Table 5). This finding is consistent with $61 \%$ sometimes sharing program level outcomes as described previously.

With regard to the attainment of organizational outcomes via collaborating with other faculty, the most respondents $(51 \%)$ claimed that they did that only sometimes. Interestingly, only $36 \%$ of faculty reported that they often collaborated in attaining organizational outcomes in comparison to $50 \%$ who often collaborated in achieving program level outcomes (see Table 4 and 5). These results coincide with the Ory and Parker (1989) study that indicated an overall absence of organizational efforts related to learning outcomes. 
Table 5

Research Question One: Development and Use of Organizational Level Outcomes by Faculty

\begin{tabular}{|c|c|c|c|c|c|c|c|}
\hline \multirow[b]{2}{*}{ Organizational Level Outcomes } & \multicolumn{5}{|c|}{ Frequency of Outcomes } & \multirow[b]{2}{*}{$M$} & \multirow[b]{2}{*}{$S D$} \\
\hline & $N$ & $\begin{array}{c}\text { Always } \\
\%\end{array}$ & $\begin{array}{c}\text { Often } \\
\%\end{array}$ & $\begin{array}{c}\text { Sometimes } \\
\%\end{array}$ & $\begin{array}{c}\text { Never } \\
\%\end{array}$ & & \\
\hline Connected to mission & 87 & 21 & 42 & 32 & 5 & 2.79 & 0.82 \\
\hline Attained by collaborating & 89 & 9 & 36 & 51 & 4 & 2.49 & 0.72 \\
\hline Shared with learners & 89 & 9 & 26 & 57 & 8 & 2.36 & 0.76 \\
\hline
\end{tabular}

Note. The item responses were made on a 4 -point Likert scale $(1=$ never, $4=$ always $)$. 
Second element of effective assessment- Designing assessment measures.

In addition to examining learning outcomes, the first research question was also investigated through questions in Section D of the survey, which focused on developing assessment measures. The quantitative data were analyzed using frequencies and means. Two of the survey items required participants to attach samples of data gathering measures, which were then analyzed using qualitative techniques.

With regard to using data gathering measures to assess the attainment of outcomes, most faculty (45\%) indicated that they often did so (see Table 6). When faculty were asked about their use of direct measures such as demonstrations, it was determined that $31 \%$ of faculty either always or often required learners to demonstrate what they had learned. As for indirect measures such as self-reporting, $33 \%$ of faculty always or often required learners to self-report what they thought they had learned (see Table 6).

Surprisingly, $24 \%$ of faculty never used multiple assessment measures to help compensate for the limitations of a single measure (see Table 6). This finding was supported by a national study, which found that higher education institutions more often use single, traditional assessment methods (Peterson \& Einarson, 2001). 
Table 6

Research Question One: Use of Assessment Measures by Faculty

\begin{tabular}{|c|c|c|c|c|c|c|c|}
\hline \multirow[b]{2}{*}{ Faculty Use of Assessment Measures } & \multicolumn{5}{|c|}{ Frequency of Use of Assessment Measures } & \multirow[b]{2}{*}{$M$} & \multirow[b]{2}{*}{$S D$} \\
\hline & $N$ & $\begin{array}{c}\text { Always } \\
\%\end{array}$ & $\begin{array}{c}\text { Often } \\
\%\end{array}$ & $\begin{array}{c}\text { Sometimes } \\
\%\end{array}$ & $\begin{array}{c}\text { Never } \\
\%\end{array}$ & & \\
\hline Assessed outcome attainment & 95 & 6 & 45 & 41 & 8 & 2.48 & 0.74 \\
\hline Used direct measures & 96 & 7 & 24 & 54 & 15 & 2.24 & 0.79 \\
\hline Used indirect measures & 95 & 6 & 27 & 53 & 14 & 2.26 & 0.77 \\
\hline Used multiple measures & 95 & 8 & 24 & 44 & 24 & 2.15 & 0.87 \\
\hline Developed own measures & 94 & 17 & 26 & 32 & 25 & 2.36 & 1.04 \\
\hline Used statewide measures & 96 & 4 & 25 & 45 & 26 & 2.07 & 0.82 \\
\hline Used others' measures & 94 & 2 & 10 & 39 & 49 & 1.65 & 0.74 \\
\hline Designed within discipline & 95 & 1 & 15 & 52 & 32 & 1.85 & 0.70 \\
\hline Designed outside discipline & 96 & 0 & 10 & 32 & 58 & 1.53 & 0.68 \\
\hline
\end{tabular}

Note. The item responses were made on a 4 -point Likert scale $(1=$ never, $4=$ always $)$. 
When designing assessment measures at the program level, $32 \%$ claimed that they never collaborated with faculty in their program area. This is in comparison to 58\% who claimed that they never designed assessment measures with faculty outside of their program area (see Table 6). This links to the lack of collaboration in outcome development discussed previously and the lack of collaboration in creating educational experiences and in discussing assessment results that will both be described later in this discussion.

When faculty were asked about their frequency of developing their own assessment measures, $43 \%$ claimed that they always or often developed their own instruments (see Table 6). As a follow-up to this item, faculty were asked to attach samples of assessment instruments that they had designed. This request resulted in 47 assessment measure samples submitted by respondents.

After coding and analyzing the content of the surveys, the majority of the instruments were found to be indirect measures. This included 29 instruments (62\%) in which learners were required to self-report what they thought they had learned (see Table 7). Of the 29 measures, nine assessed the cognitive learning domain while two examined outcomes in the affective domain. Nine of the indirect instruments measured learning in the psychomotor domain. All three learning domains were addressed through questions in nine of the indirect instruments. Examples of indirect measures in each of the three domains are found in Table 8.

The remaining 18 instruments (38\%) were direct measures of student learning which asked learners to demonstrate their knowledge and skills as they responded to the instrument. After analyzing the direct measures for various dimensions of learning, the 
largest number of instruments $(\mathrm{n}=10)$ measured the cognitive learning domain. There were five measures that included questions in the psychomotor domain. Three instruments were submitted which included questions from all three learning domains (see Table 7). Examples of direct measures in each of the three domains are found in Table 8.

Table 7

Research Question One: Types of Assessment Measures Developed by Faculty

\begin{tabular}{lccc}
\hline & Direct Measures & Indirect Measures & Total Measures \\
\multicolumn{1}{c}{ Learning Domain } & $\mathrm{N}$ & $\mathrm{N}$ & $\mathrm{N}$ \\
\hline Cognitive Domain & 10 & 9 & 19 \\
Affective Domain & 0 & 2 & 2 \\
Psychomotor Domain & 5 & 9 & 14 \\
Combination of all three & 3 & 9 & 12 \\
Total & 18 & 29 & 47 \\
\hline
\end{tabular}

Note. The data indicate the number of documents returned by respondents that measure certain domains of learning and specific types of assessment instruments. 
Table 8

Research Question One: Examples of Measures in Each Domain Developed by Faculty

$\begin{array}{lll}\text { Learning Domain } \quad \text { Direct Examples } & \text { Indirect Examples }\end{array}$

Cognitive Domain

Affective Domain

Psychomotor Domain
An 8 row (30") corn planter with liquid fertilizer attachments applies 10 fluid oz./row in 109 feet. How many gallons/acre are being applied?

_. gallons/acre

Based on the diabetes nutrition information presented, discuss the value and worth of the content of this information, as well as your attitude toward the information.

Demonstrate the appropriate application of pesticides to certain crops.
As a result of this class, to what extent do you feel more knowledgeable about criteria used to evaluate your personal financial situation? Great extent

Some

I have changed my attitude toward setting personal goals and plans, which I am putting into actions to improve my life situation.

$$
\begin{aligned}
& \text { Yes } \\
& \hline \mathrm{No}
\end{aligned}
$$

I now cook hamburger patties until they are no longer pink in the middle, and the juices are yellowish-clear.

Yes

No

Note. The data indicate examples of questions that were provided on the requested documents returned by respondents. 
Another similar survey item asked respondents about their frequency of using measures developed by other professionals or institutions and also asked for samples to be attached. The largest proportion of respondents (49\%) indicated that they never used assessment measures developed by other professionals or institutions (see Table 6).

Only 15 documents developed by others were submitted by respondents. Of the total, eight were direct measures and seven were indirect measures of student learning. There were five instruments that measured cognitive learning and five that examined psychomotor skills. Finally, there were five measures that investigated all three domains of student learning.

These two qualitative survey items, that requested attachments of assessment instruments, resulted in a total of 92 documents submitted. As stated previously, there were 47 documents $(51 \%)$ submitted that were developed by the respondents and 15 (16\%) documents submitted that were developed by other professionals or institutions.

The qualitative analysis found that the remaining 30 instruments (33\%) were not assessments of student learning. Three main categories emerged from the data in which instruments were then coded and placed. There were 10 documents that focused on the learners' reactions to the class, location, facilities or process, not their learning. Three of the instruments only measured teaching effectiveness while four gathered learners' demographic information. Finally, 13 of the documents combined questions that addressed learners' reactions, teaching effectiveness, and demographic information.

Third element of effective assessment- Creating effective educational experiences.

The last section of the survey focused on the third vital assessment utilization element of creating effective educational experiences. These data were collected from 
items 55 through 58 of the survey. The data revealed that the majority of faculty (49\%) often used a variety of teaching techniques to achieve learner outcomes. Over one-half of faculty (54\%) often delivered an interrelated set of educational experiences (see Table 9).

Faculty also reported their frequency of collaborative efforts in designing educational experiences with faculty inside and outside of their program areas. Only $6 \%$ of the respondents claimed that they never collaborated within their program area while $33 \%$ never designed educational experiences with faculty outside of their program area (see Table 9). This trend supported the previously discussed lack of collaboration among faculty with regard to other key assessment practices. These results were in alignment with a national study which demonstrated that course and program level assessments were more often implemented than institution-wide assessment efforts (Peterson \& Einarson, 2001). 
Table 9

Research Question One: Development of Educational Experiences by Faculty

\begin{tabular}{|c|c|c|c|c|c|c|c|}
\hline \multirow[b]{2}{*}{ Development of Educational Experiences } & \multicolumn{5}{|c|}{ Frequency of Experience Development } & \multirow[b]{2}{*}{$M$} & \multirow[b]{2}{*}{$S D$} \\
\hline & $N$ & $\begin{array}{c}\text { Always } \\
\%\end{array}$ & $\begin{array}{l}\text { Often } \\
\%\end{array}$ & $\begin{array}{c}\text { Sometimes } \\
\%\end{array}$ & $\begin{array}{c}\text { Never } \\
\%\end{array}$ & & \\
\hline Included variety of techniques & 97 & 40 & 49 & 11 & 0 & 3.29 & 0.66 \\
\hline Included interrelated experiences & 93 & 19 & 54 & 23 & 4 & 2.88 & 0.76 \\
\hline Designed within discipline & 97 & 5 & 22 & 67 & 6 & 2.26 & 0.65 \\
\hline Designed outside discipline & 97 & 2 & 16 & 49 & 33 & 1.87 & 0.75 \\
\hline
\end{tabular}

Note. The item responses were made on a 4 -point Likert scale $(1=$ never, $4=$ always $)$. 


\section{Research Question Two - Benefits of Implementing Assessment}

The second research question focused on what Maryland Cooperative Extension faculty perceived to be the benefits of implementing assessment. The items that addressed this research question were in Section A of the survey, which included questions one through 15 . The items were in a five-point Likert scale so that respondents could describe how strongly they agreed or disagree with statements of potential benefits of implementing assessment. The items included the following responses: the number five represented strongly agree, four represented agree; three represented neutral; two represented disagree; and one represented strongly disagree. The data from the items were analyzed using frequencies and means. At the end of that section of the survey, there was also one open-ended question that asked participants to identify any additional benefits that they had experienced in implementing assessment. This component required a qualitative analysis that included coding and analyzing the data.

Of the list of benefits provided to participants, there was one benefit that was overwhelmingly agreed with. The concept was that assessment helped to determine if their learners had developed appropriate knowledge and skills. There were $46 \%$ of respondents who strongly agreed with that statement. On a similar item, $38 \%$ of faculty strongly agreed that assessment allowed them to determine if the curriculum was contributing to student learning (see Table 10). One respondent stated, "Assessment allows me to adapt and fine tune the curriculum through time." 
Table 10

Research Question Two: Faculty Perceptions of the Benefits of Assessment

\begin{tabular}{|c|c|c|c|c|c|c|c|c|}
\hline \multirow[b]{2}{*}{ Assessment Benefits } & \multirow[b]{2}{*}{$N$} & \multicolumn{5}{|c|}{ Level of Agreement } & \multirow[b]{2}{*}{$M$} & \multirow[b]{2}{*}{$S D$} \\
\hline & & $\begin{array}{c}\text { Strongly } \\
\text { Agree } \\
\%\end{array}$ & $\begin{array}{c}\text { Agree } \\
\%\end{array}$ & $\begin{array}{c}\text { Neutral } \\
\%\end{array}$ & $\begin{array}{c}\text { Disagree } \\
\%\end{array}$ & $\begin{array}{c}\text { Strongly } \\
\text { Disagree } \\
\%\end{array}$ & & \\
\hline Develop knowledge in learners & 98 & 46 & 42 & 11 & 1 & 0 & 4.33 & 0.71 \\
\hline Determine if curriculum working & 97 & 38 & 51 & 8 & 3 & 0 & 4.23 & 0.73 \\
\hline Improve teaching & 97 & 27 & 45 & 24 & 4 & 0 & 3.95 & 0.82 \\
\hline Identify changes for future & 97 & 41 & 47 & 11 & 1 & 0 & 4.27 & 0.70 \\
\hline Inform learners of expectations & 96 & 13 & 41 & 37 & 9 & 0 & 3.57 & 0.83 \\
\hline Interact within discipline & 98 & 9 & 31 & 33 & 25 & 2 & 3.20 & 0.98 \\
\hline Interact outside discipline & 98 & 7 & 20 & 40 & 28 & 5 & 2.97 & 0.99 \\
\hline Value in promotion and tenure & 97 & 26 & 36 & 23 & 6 & 9 & 3.63 & 1.20 \\
\hline Use for annual faculty report & 98 & 36 & 40 & 5 & 14 & 5 & 3.87 & 1.20 \\
\hline Lead to publishing/presenting & 97 & 22 & 29 & 28 & 8 & 13 & 3.37 & 1.29 \\
\hline Expand funding opportunities & 97 & 19 & 32 & 33 & 5 & 11 & 3.41 & 1.19 \\
\hline Understand diverse learner needs & 96 & 19 & 47 & 23 & 8 & 3 & 3.70 & 0.97 \\
\hline Gain stakeholder support & 98 & 14 & 53 & 24 & 6 & 3 & 3.69 & 0.90 \\
\hline Provide planning information & 96 & 20 & 48 & 24 & 6 & 2 & 3.77 & 0.91 \\
\hline Participate in trainings & 97 & 8 & 42 & 23 & 17 & 10 & 3.22 & 1.14 \\
\hline
\end{tabular}

Note. The item responses were made on a 5-point Likert scale ( $1=$ strongly disagree, $5=$ strongly agree $)$. 
In addition to planning for future classes, the majority of faculty (48\%) agreed that assessment provided critical information for strategic and program planning. Only $8 \%$ disagreed or strongly disagreed that it was used for those planning purposes (see Table 10). These findings were concurrent with the Williford (1997) study that found assessment to be beneficial for strategic and program planning.

Overwhelmingly, $76 \%$ of faculty agreed or strongly agreed that using assessment for annual faculty reports was a benefit. Nearly $62 \%$ of faculty agreed or strongly agreed that it was beneficial to use assessment in the promotion and tenure process. Also, $51 \%$ of faculty agreed or strongly agreed that assessment led to opportunities for presenting or publishing. (see Table 10). When asked about assessment expanding funding opportunities, the highest response category was neutral at $33 \%$ but $51 \%$ agreed or strongly agreed. There were $53 \%$ of respondents who agreed that assessment results were shared with stakeholders to help gain support (see Table 10).

Benefits of assessment at the organizational and program levels were also addressed. Over one-quarter of faculty disagreed or strongly disagreed that assessment allowed them to interact in their program area while 33\% disagreed or strongly disagreed that it allowed them to interact with faculty outside of their program area (see Table 10). This finding supported the previously discussed results related to the lack of collaboration among faculty with regard to key assessment practices.

Qualitatively, two of the faculty respondents claimed that a benefit of assessment was that it resulted in personal satisfaction and accomplishment. Respondents also reported the following benefits of assessment: immediate feedback, affirmation, appreciation, and constructive criticism. 


\section{Research Question Three - Challenges of Implementing Assessment}

The third research question focused on what faculty perceived to be the challenges of implementing assessment. The items that addressed this research question were in Section B of the survey, which included questions 16 through 30. The items were in a five-point Likert scale so that respondents could describe how strongly they agreed or disagree with statements of potential challenges of implementing assessment.

There was one open-ended question that asked faculty to identify any additional challenges that they had experienced in implementing assessment. Another open-ended question appeared at the end of the survey, which allowed faculty to share any additional information about assessment. This resulted in a number of assessment challenges being reported. Both of these questions required a qualitative analysis, which included coding and analyzing the data.

The largest number of respondents agreed with the assessment challenge related to the fact that colleagues do not value assessment. Overwhelmingly, $64 \%$ of faculty either agreed or strongly agreed that colleagues do not value assessment (see Table 11). This finding was supported by Muffo's (1992) study of 73 NASULGC member institutions where the lack of faculty involvement was identified as a critical assessment issue. 
Table 11

Research Question Three: Faculty Perceptions of the Challenges of Assessment

\begin{tabular}{|c|c|c|c|c|c|c|c|c|}
\hline \multirow[b]{2}{*}{ Assessment Challenges } & \multicolumn{7}{|c|}{ Level of Agreement } & \multirow[b]{2}{*}{$S D$} \\
\hline & $N$ & $\begin{array}{c}\text { Strongly } \\
\text { Agree } \\
\%\end{array}$ & $\begin{array}{c}\text { Agree } \\
\%\end{array}$ & $\begin{array}{c}\text { Neutral } \\
\%\end{array}$ & $\begin{array}{c}\text { Disagree } \\
\%\end{array}$ & $\begin{array}{c}\text { Strongly } \\
\text { Disagree } \\
\%\end{array}$ & $M$ & \\
\hline Lack assessment resources & 98 & 10 & 35 & 16 & 32 & 7 & 3.09 & 1.17 \\
\hline Lack understanding of practices & 98 & 7 & 28 & 24 & 38 & 3 & 2.98 & 1.04 \\
\hline Instruments too expensive & 97 & 3 & 6 & 43 & 42 & 6 & 2.58 & 0.83 \\
\hline Assessment too complex & 97 & 1 & 17 & 27 & 42 & 13 & 2.50 & 0.96 \\
\hline Lack time to study assessment & 98 & 11 & 35 & 23 & 27 & 4 & 3.22 & 1.09 \\
\hline Lack time to carry out assessment & 98 & 9 & 28 & 31 & 28 & 4 & 3.10 & 1.04 \\
\hline Lack support from administration & 98 & 18 & 34 & 24 & 18 & 6 & 3.41 & 1.16 \\
\hline Findings used for promotion & 98 & 8 & 30 & 34 & 24 & 4 & 3.13 & 1.01 \\
\hline Data used for external audiences & 97 & 3 & 16 & 49 & 27 & 5 & 2.85 & 0.86 \\
\hline Question validity/reliability & 96 & 14 & 37 & 20 & 27 & 2 & 3.32 & 1.08 \\
\hline Learners resist assessment & 98 & 18 & 40 & 17 & 24 & 1 & 3.51 & 1.08 \\
\hline
\end{tabular}

Note. The item responses were made on a 5-point Likert scale ( $1=$ strongly disagree, $5=$ strongly agree $)$. 
The lack of value and importance of assessment from administration was also viewed as a challenge of assessment. There were $52 \%$ of the faculty who agreed or strongly agreed that administration support was absent. One respondent commented that there was a "complete lack of direction, training, and consistency for conducting assessment". Another felt that "guidance and encouragement was needed from program leaders and regional extension directors to help monitor and encourage active programming and assessment". She felt that a much "more interactive, hands-on approach was needed for the collective assessment process to occur". One other respondent claimed that administration needed to focus more on assessment "by hiring assessment specialists to provide expertise and professional guidance to faculty". Other faculty described administration-related challenges such as "lack of infrastructure, leadership, and program support”. These quantitative and qualitative data were concurrent with findings from a previous study that found only $6 \%$ of institutions had participation and support for assessment from administrators (Peterson \& Einarson, 2001).

The study also found that faculty viewed the lack of rewards for assessment efforts as a challenge to implementing assessment (see Table 11). As evidence of this, one respondent described that he lacked "motivation to utilize assessment in his educational programming." Another faculty member claimed that there were "few, if any, job-related benefits of implementing assessment".

As for the expense of developing assessment instruments, the largest percentage of faculty (43\%) were neutral about the challenge while $42 \%$ disagreed that cost was a challenge (see Table 11). These results were in contrast to the Chapman-Novakofski and 
Associates (1997) study that cited the cost of assessment as a significant barrier to implementation for Extension faculty.

When asked about their level of training for carrying out assessment, the largest proportion of faculty (41\%) agreed that they lacked sufficient training (see Table 11). One respondent felt that there was an "enormous need" for training among faculty. She felt that it should focus on how to "allow time for accurate and useful assessments as part of the program planning process." Another stated that assessment training should be mandatory for all faculty and be conducted on a regular, continual basis.

Even with the large proportion of faculty lacking assessment training, $42 \%$ of respondents disagreed that assessment was too complex and difficult to implement. The highest proportion of faculty (38\%) also disagreed that they lacked an understanding of assessment practices (see Table 11). These findings were in contrast to an earlier Extension study that found that $42 \%$ of faculty lacked essential assessment skills (West Virginia University, 1979).

The questionable validity and reliability of assessment instruments were of concern to $51 \%$ of faculty who agreed or strongly agreed that these issues served as challenges to the process (see Table 11). One faculty member claimed that the validity and reliability of tools were in doubt because of the diversity of audiences. Another felt that the "current standardized tools were inadequate and asked the wrong questions. Also, the lack of consistency in assessment made it impossible to make comparisons across the state." Two respondents also stated that the reading level and age appropriateness of instruments served as a challenge for 4-H-aged learners. 
The challenge related to the lack of time for carrying out assessment activities resulted in the largest proportion of respondents (31\%) claiming a neutral response with an equal number agreeing $(28 \%)$ and disagreeing $(28 \%)$ that time was a challenge (see Table 11). These results were not in alignment with a previous Extension study, which found that $64 \%$ of faculty lacked time to implement assessment (West Virginia University, 1979).

Even though the quantitative findings related to time did not support the previous study, many qualitative comments maintained that time served as a challenge. One respondent stated that he was "not willing to use a significant portion of his time intended for student learning on assessment." Another stated, "People who construct assessment tools woefully underestimate the time required to thoughtfully answer the survey."

In contrast, the time required for studying the assessment process was identified as a challenge. The largest proportion of respondents (35\%) agreed that they lacked time to study assessment. One faculty member felt that there was "no planning time to figure out how to actually develop and use new assessment tools." Also, the largest percentage of faculty (35\%) agreed that they lacked assessment resources while $32 \%$ agreed that they lacked secretarial support for entering assessment data (see Table 11).

Finally, faculty indicated that learners' resistance to completing tests and surveys was a challenge. The highest percentage of faculty (40\%) agreed with this statement (see Table 11). In support of this, one respondent claimed that learners "are too lazy or in too much of a hurry to do assessments." Another noted that a challenge was in determining if learners actually made the behavior changes that they claimed to, following an educational program. In support of these data were the results of Muffo's (1992) study 
which indicated that learner cooperation with assessment efforts was a major concern. Also, these findings were concurrent with an Extension study that found that learners were resistant to completing assessments due to literacy issues and time constraints (Chapman-Novakofski et al., 1997).

According to one respondent, a huge assessment challenge was in seeking institutional review board approval since it was "too lengthy, restrictive, and cumbersome." Finally, one faculty member described assessment as the "epoxy that greases the wheels of progress. We have too much bureaucracy already." Research Question Four - Use of Assessment Results

The fourth research question focused on how faculty used the results of assessment to make improvements. The items that addressed this research question were in Section F of the survey, which included questions 59 through 71 . The items were in a four-point Likert scale, ranging from always to never, so that respondents could describe how often they used certain results of assessment. The data from the items were analyzed using frequencies and means.

Assessment results were used in a variety of ways by Extension faculty in this study. Twenty-seven percent of faculty always used their assessment results for improving learner performance on outcomes. Almost one-third of respondents (31\%) always used assessment results to improve their teaching while $26 \%$ always used the results to improve their curriculum (see Table 12). These findings were in agreement with a previous study that discovered that faculty were using assessment results to improve their programs and curricula (Williford, 1997). 
In addition to using assessment results to benefit the learners, $29 \%$ of faculty always utilized the information for their own purposes such as reporting progress on their annual reports (see Table 12). Only $14 \%$ of faculty always used assessment results for planning and budgeting decisions. This coincided with a previous study that found that assessment results had only a marginal effect in decision-making (Peterson \& Augustine, 2000). These results were also supported by West Virginia University study (1979) where only $33 \%$ of Extension faculty felt that results were used for decision-making.

The largest proportion of faculty (43\%) only sometimes used the results to verify that assessment was working (see Table 12). Peterson and Einarson (2001) found similar results in that only $50 \%$ of institutions surveyed actually evaluated their own assessment practices. As for external uses of assessment results, $27 \%$ of respondents never used the results to market programs to potential clientele. In addition, $22 \%$ never used the results to secure funding from stakeholders (see Table 12).

With regard to recognition for quality, the highest proportion of faculty (41\%) indicated that they only sometimes used assessment results to get recognized for quality programs. The largest percentage of faculty (39\%) only sometimes used assessment results for accountability while $35 \%$ sometimes used results to meet statewide mandates (see Table 12). One faculty member felt that Cooperative Extension "should better coordinate and utilize the results of assessment statewide."

In general, faculty more often discussed assessment results with faculty in their own program area than with faculty outside of their program (see Table 12). Amazingly, $38 \%$ of respondents never discussed assessment results, as they relate to organizational outcomes, with faculty outside of their program area (Table 12). 
Table 12

Research Question Four: Uses of Assessment Results by Faculty

\begin{tabular}{|c|c|c|c|c|c|c|c|}
\hline \multirow[b]{2}{*}{ Uses of Assessment Results } & \multicolumn{7}{|c|}{ Frequency of Uses of Results } \\
\hline & $N$ & $\begin{array}{c}\text { Always } \\
\%\end{array}$ & $\begin{array}{c}\text { Often } \\
\%\end{array}$ & $\begin{array}{c}\text { Sometimes } \\
\%\end{array}$ & $\begin{array}{c}\text { Never } \\
\%\end{array}$ & $M$ & $S D$ \\
\hline Curriculum improvement & 95 & 26 & 46 & 26 & 2 & 2.96 & 0.78 \\
\hline Teaching improvement & 97 & 31 & 45 & 20 & 4 & 3.03 & 0.82 \\
\hline Outcomes improvement & 97 & 27 & 37 & 33 & 3 & 2.88 & 0.84 \\
\hline Planning/budgeting decisions & 96 & 14 & 32 & 41 & 13 & 2.49 & 0.97 \\
\hline Annual faculty reports & 97 & 29 & 38 & 22 & 11 & 2.85 & 0.97 \\
\hline Funding from stakeholders & 97 & 7 & 35 & 36 & 22 & 2.28 & 0.89 \\
\hline Statewide mandates & 93 & 14 & 31 & 35 & 20 & 2.39 & 0.97 \\
\hline Recognition for quality & 96 & 10 & 38 & 41 & 11 & 2.47 & 0.83 \\
\hline Market programs to clientele & 96 & 13 & 30 & 30 & 27 & 2.28 & 1.00 \\
\hline Accountability & 95 & 13 & 32 & 39 & 16 & 2.42 & 0.91 \\
\hline Assessment verification & 93 & 9 & 25 & 43 & 23 & 2.18 & 0.90 \\
\hline Discuss within discipline & 97 & 6 & 27 & 45 & 22 & 2.18 & 0.84 \\
\hline Discuss outside discipline & 96 & 3 & 10 & 49 & 38 & 1.79 & 0.75 \\
\hline
\end{tabular}

Note. The item responses were made on a 4 -point Likert scale $(1=$ never, $4=$ always $)$. 
Research Question Five - Difference in Assessment Utilization Across Disciplines

The fifth research question focused on whether there was a statistically significant difference among faculty across disciplines (agriculture, youth development, and family and consumer sciences) regarding their utilization of assessment. The items that addressed this research question were item 73 which was the independent variable of discipline, and items 31 through 71 which were the dependent variables in survey Sections C, D, E, and F. Each section addressed one of the four essential elements of effective utilization of assessment. The items were in a four-point Likert scale, ranging from always to never, so that respondents could describe how often they carried out certain assessment-related tasks.

In order to determine if there were statistically significant differences among faculty, MANOVAs were calculated for each section or subsection of the survey that addressed assessment utilization. If significant, ANOVAs were calculated for each dependent variable with a Post Hoc Tukey HSD.

First element of effective assessment- Developing learning outcomes.

The first essential element of assessment utilization that was examined focused on developing learning outcomes at the class, program, and organizational levels.

\section{Class level outcomes}

First, a MANOVA was calculated examining the effect of faculty discipline (agriculture, youth development, family and consumer sciences) on use of class level outcome elements. No statistically significant difference was found $(\operatorname{Lambda}(14,158)=$ $1.21, p=.27)$. None of the seven class level outcome practices were significantly different based on faculty discipline. 


\section{Program level outcomes}

A MANOVA was calculated examining the effect of faculty discipline (agriculture, youth development, family and consumer sciences) on the use of program level outcomes. A significant effect was found $(\operatorname{Lambda}(8,160)=2.21, p=.03)$. Follow-up analyses of variance on the four survey items indicated that the concept of connecting the organization's mission, vision, and values to program level outcomes was statistically significantly influenced by faculty discipline $(F(2,89)=3.64, p=.03)$. Tukey's HSD was used to determine the nature of the difference among the faculty with regard to this item. This analysis revealed that family and consumer science faculty more often $(M=3.40, S D=0.60)$ connected the mission, vision, and values to the program outcomes than agriculture faculty $(M=2.89, S D=0.80)$. With regard to this element, the youth development faculty $(M=3.19, S D=0.75)$ were not statistically significantly different from either of the other two groups (see Table 13).

Analyses of variance were calculated for the other three program level outcome survey items and no statistically significant differences were found. For example, faculty did not vary significantly among discipline with regard to achieving program level outcomes through delivering classes $(F(2,88)=2.36, p=.10)$. No significant differences were found among different faculty disciplines with respect to attaining program outcomes by collaborating with other faculty $(F(2,88)=1.56, p=.22)$ or in sharing program outcomes with the public $(F(2,86)=1.32, p=.27)$. See Table 13 for a summary. 
Table 13

Research Question Five: Outcome Practices Among Faculty of Different Disciplines

\begin{tabular}{|c|c|c|c|c|c|}
\hline \multirow[b]{3}{*}{ Program Outcome Practice } & \multicolumn{4}{|c|}{ Family \& } & \multirow{2}{*}{$\begin{array}{c}\text { Youth } \\
\text { Development }\end{array}$} \\
\hline & & & Cons. Science & Agriculture & \\
\hline & $F$ & $p$ & $M$ & $M$ & $M$ \\
\hline Connected to mission & 3.64 & $.03 *$ & 3.40 & 2.89 & 3.19 \\
\hline Achieved through classes & 2.36 & .10 & 3.10 & 2.71 & 2.93 \\
\hline Attained by collaborating & 1.56 & .22 & 2.57 & 2.62 & 2.93 \\
\hline Shared with learners & 1.32 & .27 & 2.33 & 2.25 & 2.60 \\
\hline
\end{tabular}

Note. The program outcome practices were made on 4-point Likert scales $(1=$ never, 4 = always).

$* \mathrm{p}<.05$

\section{Organizational level outcomes}

With regard to the use of organizational outcomes among faculty, a MANOVA was calculated examining the effect of faculty discipline (agriculture, youth development, family and consumer sciences). No statistically significant difference was found $(\operatorname{Lambda}(6,160)=.23, p=.97)$ among faculty disciplines with regard to organizational outcome practices.

Second element of effective assessment- Designing assessment measures.

The second essential element of assessment utilization that was examined for research question five was that of designing assessment measures. A MANOVA was calculated examining the effect of faculty discipline (agriculture, youth development, 
family and consumer sciences) on designing assessment measures. A significant effect was found $(\operatorname{Lambda}(18,150)=1.98, p=.01)$. Due to the significant result, analyses of variance were then calculated for the nine survey items.

No statistically significant difference was found $(F(2,90)=1.57, p=.21)$ among faculty of various disciplines with regard to their frequency of developing assessment measures (see Table 14). However, faculty did differ by discipline on their use of statewide assessment measures $(F(2,92)=4.67, p=.01)$. A Tukey HSD analysis indicated that family and consumer science faculty more often utilized statewide assessment measures $(M=2.45, S D=0.80)$ than agriculture faculty $(M=1.88, S D=$ $0.82)$. The youth development faculty $(M=2.27, S D=0.70)$ were not statistically significantly different from either of the other two groups with regard to this concept (see Table 14).

There was a statistically significant difference among faculty with regard to using assessment measures developed by other professionals or institutions $(F(2,90)=$ $12.35, p<.01)$. A post-hoc analysis was conducted to determine the nature of the difference among the faculty. This analysis revealed that youth development faculty $(M$ $=2.00, S D=0.71)$ more often used assessment measures developed by others than agriculture faculty $(M=1.38, S D=0.64)$. The same holds true for family and consumer science faculty $(M=2.14, S D=0.71)$ when compared to agriculture faculty but not when compared to youth development faculty (see Table 14).

Faculty in different disciplines also varied significantly in their use of multiple types of assessment measures to compensate for the limitations of single measures. A statistically significant difference was found $(F(2,91=5.92, p<.01)$. A Tukey HSD 
analysis indicated that family and consumer science faculty more often utilized various assessment measures $(M=2.57, S D=0.68)$ than agriculture faculty $(M=1.91, S D=$ $0.83)$. The youth development faculty $(M=2.44, S D=1.03)$ were not statistically significantly different from either of the other two groups in using multiple assessment measures (see Table 14).

When examining faculty differences related to the design of assessment measures collaboratively within their discipline, an ANOVA revealed a statistically significant difference by discipline $(F(2,91)=7.00, p<.01)$. A post-hoc analysis determined that youth development faculty $(M=2.25, S D=0.68)$ collaborated with colleagues in their discipline when designing assessment measures more often than agriculture faculty $(M=$ $1.65, S D=0.67)$. The same holds true for family and consumer science faculty $(M=$ $2.10, S D=0.62$ ) when compared to agriculture faculty but not when compared to youth development faculty (see Table 13). In contrast, faculty did not differ significantly $(F(2,92)=2.25, p=.11)$ in their responses regarding the design of assessment measures with faculty outside of their discipline or program area (see Table 14). 
Table 14

Research Question Five: Assessment Measure Practices By Faculty Discipline

\begin{tabular}{|c|c|c|c|c|c|}
\hline \multirow{3}{*}{ Use of Measures } & \multicolumn{4}{|c|}{ Family \& } & \multirow{3}{*}{$\begin{array}{c}\text { Youth } \\
\text { Development } \\
M\end{array}$} \\
\hline & & & Cons. Science & Agriculture & \\
\hline & $F$ & $P$ & $M$ & $M$ & \\
\hline Assessed outcomes & 3.01 & .054 & 2.75 & 2.34 & 2.68 \\
\hline Used direct measures & 5.66 & $<.01 *$ & 2.52 & 2.03 & 2.63 \\
\hline Used indirect measures & 5.25 & $<.01 *$ & 2.70 & 2.09 & 2.38 \\
\hline Used multiple measures & 5.92 & $<.01 *$ & 2.57 & 1.91 & 2.44 \\
\hline Developed own measures & 1.57 & .21 & 2.55 & 2.21 & 2.67 \\
\hline Used statewide measures & 4.67 & $.01 *$ & 2.45 & 1.88 & 2.27 \\
\hline Used others' measures & 12.35 & $<.01 *$ & 2.14 & 1.38 & 2.00 \\
\hline Designed within discipline & 7.00 & $<.01 *$ & 2.10 & 1.65 & 2.25 \\
\hline Designed outside discipline & 2.25 & .11 & 1.59 & 1.42 & 1.81 \\
\hline
\end{tabular}

Note. The uses of assessment measures were made on 4-point Likert scales $(1=$ never, 4 = always).

$* \mathrm{p}<.05$

In addition to being asked about the design and development of measures, faculty were also surveyed about the content of the measures. Respondents did not significantly vary, according to ANOVA results, in their responses about using assessment measures to evaluate the attainment of established learning outcomes $(F(2,91)=3.01, p=.054)$. 
The faculty from the three disciplines did not differ significantly in their frequency of using measures to assess outcome attainment (see Table 14).

In examining the differences related to faculty responses about using direct measures which require learners to demonstrate their learning, an ANOVA revealed a statistically significant difference by faculty discipline $(F(2,92)=5.66, p<.01)$.

Tukey's HSD post-hoc analysis revealed that youth development faculty $(M=2.63, S D=$ 0.89) required learners to demonstrate their learning on assessment measures more often than agriculture faculty $(M=2.03, S D=0.72)$. The same holds true for family and consumer science faculty $(M=2.52, S D=0.75)$ when compared to agriculture faculty but not when compared to youth development faculty (see Table 14).

Faculty in the three disciplines also varied with regard to using indirect measures where learners self-report their learning. An ANOVA was calculated and found a statistically significant difference by faculty discipline $(F(2,91)=5.25, p<.01)$. The Tukey's HSD revealed that family and consumer science faculty required learners to selfreport their learning on assessment measures more often $(M=2.70, S D=0.66)$ than agriculture faculty $(M=2.09, S D=0.80)$. The youth development faculty $(M=2.38, S D$ $=0.62$ ) were not statistically significantly different from either of the other two groups with regard to this concept (see Table 14).

Third element of effective assessment- Creating effective educational experiences.

The third essential element of assessment utilization was the concept of creating Extension education experiences. Using the four survey items, a MANOVA was calculated examining the effect of faculty discipline (agriculture, youth development, family and consumer sciences) on creating educational experiences. No statistically 
significant difference was found $(\operatorname{Lambda}(8,172)=.97, p=.46)$ among faculty of different disciplines with regard to creating Extension educational experiences.

Fourth element of effective assessment- Using assessment results.

Faculty also did not vary significantly on their practices related to using assessment results. Using the 13 survey items, a MANOVA was calculated examining the effect of faculty discipline (agriculture, youth development, family and consumer sciences) on using assessment results. No statistically significant difference was found $(\operatorname{Lambda}(26,144)=.99, p=.49)$.

Research Question Six - Difference in Assessment Utilization Across Ranks

The sixth research question focused on whether there was a statistically significant difference among faculty across different ranks (full-professor-principal agent, associate professor-senior agent, assistant professor-agent) regarding their utilization of assessment. The items that addressed this research question were item 75 , which was the independent variable of rank, and items 31 through 71 which were the dependent variables in survey Sections C, D, E, and F. Each section addressed one of the four essential elements of effective utilization of assessment.

To determine if there was a difference among faculty of various ranks with regard to class, program, and organizational outcomes, MANOVAs were calculated for each of the three subsections of Section C of the survey. As for class level outcomes, no statistically significant difference was found $(\operatorname{Lambda}(14,154)=1.25, p=.25)$ among the three ranks in their assessment practices. Faculty also did not vary statistically with regard to their utilization of program level outcomes $(\operatorname{Lambda}(8,158)=0.36, p=.94)$ or organizational level outcomes $(\operatorname{Lambda}(6,160)=0.36, p=.90)$. 
The development of assessment measures was the second essential concept of assessment utilization that was studied for differences among faculty of various ranks. A MANOVA indicated that there was no statistically significant difference (Lambda $(18,148)=1.53, p=.09)$ among the faculty ranks of full-professor-principal agent, associate professor-senior agent, and assistant professor-agent and their practices related to designing assessment measures.

Differences among rank in the third essential element of assessment utilization, creating Extension education experiences, were examined through a MANOVA. No statistically significant difference was found $(\operatorname{Lambda}(8,168)=1.64, p=.12)$ among the ranks with regard to creating educational experiences.

The final element of assessment utilization, using assessment results, was examined for differences in practices among varying ranks of faculty. A MANOVA was calculated examining the effect of faculty rank (full-professor-principal agent, associate professor-senior agent, and assistant professor-agent) on using assessment results. No statistically significant difference was found $(\operatorname{Lambda}(26,142)=.82, p=.72)$ among faculty of different ranks and their use of assessment results.

Maryland Cooperative Extension faculty are utilizing assessment in a variety of ways through developing learning outcomes, designing assessment measures, creating educational experiences and using the assessment results. These faculty have identified countless benefits of assessment as well as a number of challenges. As for differences in utilization of assessment among faculty of different disciplines, some variances were discovered. In terms of disparities in utilization based on rank, no significant differences were found. 


\section{CHAPTER 5}

\section{Summary, Conclusions, and Recommendations}

This chapter begins with a brief review of the assessment literature followed by a review of the purpose of the study, a description of the sample, and an explanation of the methods. The second section of this chapter summarizes the major findings and presents conclusions. Finally, the last section describes recommendations for future research and practice based on the findings of the study.

\section{Summary}

With the demand for accountability and improvement in higher education continuing to increase, effective assessment programs have become vital. Assessment refers to the process of gathering data from various sources to determine how students' knowledge, attitudes, and behaviors have changed as a result of their experiences (Huba \& Freed, 2000). The assessment movement began with a focus on external accountability, which drove the majority of assessment efforts at institutions of higher education. Although the initial focus was on accountability, the attention shifted to improvement, which examined both the strengths and weaknesses of programs.

There were four essential elements of assessment that served as the basis for this study about assessment practices among Cooperative Extension faculty (Huba \& Freed, 2000). The first element involved formulating intended learning outcomes. Since outcomes have to be specific enough to measure, the second vital assessment practice was the development of data gathering measures. The third element of successful assessment emphasized the importance of integrating assessment into the creation of educational experiences. The final component of effective assessment involved 
discussing and using assessment results to improve learning (Huba \& Freed, 2000).

Although assessment requires the effective use of assessment components, it also involves a cultural shift among administration, faculty, and students.

This study explored the degree of faculty utilization of assessment practices at the class, program, and institutional levels within the University of Maryland Cooperative Extension (MCE). The study explored the differences in assessment utilization among faculty of various ranks and disciplines. This inquiry also identified what faculty believed were the benefits and challenges of implementing assessment. Finally, how faculty used the results of assessment to make improvements was examined.

The following research questions were explored in this study:

1. To what degree are Cooperative Extension faculty utilizing assessment at the class, program, and institutional levels?

2. What do faculty perceive to be the benefits of implementing assessment?

3. What do faculty perceive to be the challenges of implementing assessment?

7. How do faculty use the results of assessment to make improvements?

5. Is there a statistically significant difference among faculty across disciplines (agriculture, youth development, and family and consumer sciences) regarding their utilization of assessment?

6. Is there a statistically significant difference among faculty across different ranks (full professor-principal agent, associate professor-senior agent, assistant professor-agent) regarding their utilization of assessment?

The population for the study was Extension faculty of the University of Maryland, College Park. These faculty were located on campus and off campus at educational 
centers located in the 23 Maryland counties, Baltimore City, and at four research centers. The 175 Extension faculty at the University of Maryland taught full-time and had the following ranks: Assistant Professor- Agent; Associate Professor- Senior Agent; or Professor- Principal Agent. The faculty also differed by discipline which included the following: family and consumer sciences; agriculture and natural resources; and 4-H and youth development.

A 78-item survey was mailed, along with a personalized cover letter, to all 175 faculty members. In addition to the quantitative instrument, there were qualitative components that required respondents to give examples of learning outcomes and submit copies of assessment instruments. There were 98 completed surveys returned which resulted in a $56 \%$ response rate.

\section{Conclusions}

There were a variety of general conclusions that were drawn from the results of this research study. It was essential to discover not only how Extension faculty felt about assessment but how they were implementing the essential elements of assessment as well. Perceptions of faculty were generalized from the findings related to the assessment benefits and challenges. The strategies that faculty used for assessment were gleaned from the assessment elements data. Assessment Perceptions

The results of the research study revealed first how faculty felt about assessment and then what their actual practices entailed. The majority of faculty felt that assessment was beneficial in determining if their learners had developed the appropriate knowledge and skills. This supported Huba and Freed's (2000) notion that assessment serves as the 
basis of gathering evidence about outcome attainment. Similarly, faculty also perceived assessment to be beneficial since it allowed them to determine if their curriculum was contributing to knowledge and skill improvement. This coincides with Palomba and Banta (1999) who felt that assessment was vital for determining if the curriculum made sense. Similarly, most faculty saw the enhancement of their teaching as another assessment advantage.

The majority of the faculty felt that assessment was beneficial since it helped them identify necessary changes for future classes and access information for planning purposes. This finding supported Palomba and Banta's (1999) view that effective assessment links to processes such as program planning.

As for reporting, most faculty agreed that using assessment for annual faculty reports was a benefit. Surprisingly, faculty also believed that their assessment efforts were valued in the promotion and tenure process. This finding is concurrent with Angelo's (2002) suggestion that universities have revised their policies to include a broader definition of scholarship so that assessment may be accepted or recognized as a scholarly activity.

In addition to the benefits, faculty perceived a variety of factors to be challenges of implementing assessment. Interestingly, the majority of faculty felt that their own colleagues did not value the assessment process. This was a disturbing finding since assessment is a faculty-driven process that requires faculty acceptance and collaboration for success. Since the study demonstrated a lack of assessment collaboration among faculty, this finding related to collaboration not valuing the process was not surprising. Another reason that faculty lack value for assessment may be due to the perception that 
assessment could be a threat to their academic freedom (Banta, 2002). The lack of value could also be explained in that some faculty might feel that assessment information could be used in detrimental ways.

The lack of value and importance of assessment from administration was also viewed by faculty as a challenge of implementing assessment. This finding was in agreement with Peterson and Vaughan (2002) who pointed out that a comprehensive institutional climate must be created by administration so that faculty involvement is achieved. Banta and Associates (1996) also agreed that in order for assessment to be effective, the process must occur in "an environment that is receptive, supportive, and enabling." The actions of administration can either hinder assessment or foster it (Palomba \& Banta, 1999).

Another key challenge identified by faculty was their lack of assessment training. Interestingly, faculty viewed their lack of training as a challenge but did not view their lack of understanding or the complexity of the process as a challenge to implementation. One reason that this lack of training might have been of concern was that the training was not consistent and continuous in nature. Another explanation could have been that past trainings might not have mirrored faculty responsibility or that the basics of assessment were not fully understood before moving on to assessment methods (Palomba \& Banta, 1999).

The majority of faculty considered the questionable validity and reliability of assessment instruments a challenge. These results could be also linked to the previous challenge of lacking training, specifically with the development of instruments. This finding was in agreement with Palomba and Banta's (1999) suggestion that when faculty 
have worries about the methods used to collect assessment data, they will unlikely recognize the results or support decisions based on the information.

Finally, this research study found that faculty felt that learners' resistance to completing tests and surveys served as a challenge in implementing assessment. The reason for this finding could have been a result of the learners not fully understanding what was expected of them or that they sensed a lack of commitment from the faculty (Palomba \& Banta, 1999).

\section{Assessment Practices}

In addition to discovering how Extension faculty felt about assessment, the research study also revealed how faculty were actually using assessment. The basis for the utilization centered on the four essential elements of assessment as outlined by Huba and Freed (2000). Although there were no significant differences in assessment utilization found among faculty of different ranks, there were significant variations with certain uses of assessment among faculty in various disciplines, which will be discussed in further detail later.

In general, faculty tended to utilize effective strategies related to outcome development, which was the first element of effective assessment. The faculty mostly focused their class level outcomes on knowledge improvements of the learners. These faculty less often centered their learner outcomes on psychomotor or affective skills. This finding supported Ewell's (1983) conclusion that cognitive outcomes are more often assessed than psychomotor outcomes in higher education institutions.

As for program level outcomes, faculty often made certain that their outcomes were connected to the organizational mission. This was the only outcome-related 
assessment concept that faculty varied significantly based on discipline. Interestingly, family and consumer sciences faculty more often connected the program outcomes to the mission when compared to faculty in the agriculture program area. This difference among disciplines could be attributed to the varying standards of excellence that each discipline values (Huba \& Freed, 2000).

Unfortunately, Extension faculty did not greatly utilize the vital components of designing assessment measures, which was the second element of effective assessment. The study's findings revealed that few faculty often utilized direct or indirect measures of student learning. This could have been due to the fact that faculty were using both types of measures and did not want to denote that they were "always" using one or the other type. The lack of use of direct and indirect measures could have also been attributed to faculty using measures that assess their teaching skills and learner reactions instead of student learning. In addition, the majority did not often use multiple measures.

The source of the measures was also investigated and it was found that few faculty often used statewide assessment measures while fewer used other professionals' or institutions' assessment measures. The reason that faculty more often utilized locallydeveloped instruments could have been due to the fact that more valid inferences could be made about student learning or that the instruments could be more easily modified to reflect curriculum changes (Palomba \& Banta, 1999).

In general, it was found that family and consumer sciences faculty more often utilized the above components in comparison to agriculture faculty when developing assessment measures. The practices of youth development faculty typically ranked in between the two other program areas. 
Although assessment requires attention to learner outcomes, it also focuses on the educational experiences leading to the outcomes, which is the third essential component of effective assessment. In general, Extension faculty reported that they often included a variety of teaching techniques into the educational experiences. They also often included a variety of interrelated experiences into the curriculum. Interestingly, there were no differences among discipline with regard to these practices.

The final component of assessment practice that was uncovered involved how faculty utilized the results of assessment. It was found that Extension faculty often used assessment results for a number of purposes. Most faculty claimed that they most often used the results for teaching improvement, curriculum enhancement, and learner outcome attainment. Reporting and planning were other often utilized functions of the data. From these data, it was revealed that faculty were most often using assessment results for improvement purposes but also for accountability reasons as well.

In asking about faculty practices with regard to assessment, it was important to determine the level of collaboration that was occurring within and across disciplines. In general, the level of collaboration among faculty in implementing assessment efforts appeared to be minimal. In nearly every assessment area, faculty collaborated less with faculty outside of their discipline versus within their discipline. For example, $32 \%$ of faculty never designed assessment measures collaboratively within their program area compared to $58 \%$ who never designed measures with faculty outside their program area. To be more specific, faculty within certain disciplines, like agriculture, collaborated significantly less often within their discipline when compared to the other two disciplines. These same agriculture faculty also differed significantly from the other 
disciplines on the use of assessment measures. These differences could be attributed to the fact that faculty do not routinely collaborate with faculty in other disciplines or even with faculty within their own discipline (Banta, 2002).

The same lack of collaboration trend held true when faculty were asked about creating educational experiences. There were $6 \%$ who never collaborated within their discipline when designing educational experiences compared to $33 \%$ who never collaborated outside. Similarly, less faculty discussed the results of assessment efforts with others outside their discipline. But when asked if assessment involved interactions with other faculty, few respondents indicated that it created more interaction with faculty in the discipline and even fewer agreed that assessment involved interaction outside of the discipline. The point is that "assessment is fundamentally a collaborative process, and collaborative skills are not a hallmark of those who chose careers in academe" (Banta, 2002, p. 287).

Other interesting comparisons were made between what faculty felt were the benefits of using the results and how they actually used them. Almost one-half of faculty strongly agreed that it was beneficial to use results to affirm that outcomes were attained while only one-fourth actually did so. Faculty also felt that assessment was beneficial in helping them determine if the curriculum was working but only one-fourth were using the results for that purpose. Similarly, more faculty viewed assessment as beneficial for planning and funding purposes, but did not use the results in those ways. One area of assessment where faculty perceptions matched their practices was in relation to their annual faculty reports. 


\section{Recommendations for Future Research}

The results of this research study could lead to many additional research endeavors in assessment of student learning in higher education. First, the study should be replicated with university Extension faculty in other states. This research would further explicate the diversity of assessment approaches being used in Extension. By examining the faculty perceptions and practices about assessment in other states, broader generalizations could be made about the results. It would be useful to also compare the results of the current study with results of a study in a state where assessment is mandatory.

Broader representation could be achieved in future studies by increasing the number of faculty surveyed. Specifically, it would be useful to increase the number of faculty surveyed in each program area or discipline. Including faculty from a wider range of disciplines should be another area of investigation. Increasing the number of faculty within each professorial rank would be useful as well.

Future assessment research studies could involve a more in-depth examination of individual survey items through the incorporation of follow-up questions. There could also be an expansion of the instrument to include additional qualitative components and questions to help alleviate validity issues. In general, qualitative research related to Extension assessment would be useful. Qualitative data regarding developing learning outcomes, designing assessment measures, developing learning experiences, and using assessment results could be compared to the quantitative results of this study.

Further studies could also examine the factors that impede the use of effective assessment practices. From the current study, the vital assessment practices that faculty 
were not utilizing should be further studied. A subsequent study should examine what factors prevented faculty from utilizing those specific practices. It would be beneficial to also determine what would better motivate faculty to participate in assessment efforts.

Since the current study found differences in utilization among faculty in different disciplines, it would be interesting to further investigate the rationale for those differences. Because the agriculture faculty tended to underutilize a number of essential assessment elements, it is crucial that research be conducted to further examine these discrepancies.

One factor that should be examined with regard to this underutilization is the faculty members' educational concentrations in their own undergraduate and graduate academic work. It is thought that one explanation for these differences could be attributed to the fact that the youth development and family and consumer sciences faculty have more formal training in education in comparison to the agriculture faculty whose degrees may only focus on scientific aspects. These individuals may have not been exposed to curriculum development and design in their academic coursework. Their lack of experience with designing curricula could be an underlying factor in their underutilization of assessment. By examining their educational backgrounds in a research study, this assumption could be legitimately confirmed or denied.

Another factor that may contribute to the underutilization of assessment by agriculture faculty is learner resistance to assessment. The characteristics and makeup of the mostly farmer population of learners may impact how assessment is used. Examining this issue along with various other factors may shed light on the basis for the limited use of assessment by agriculture faculty. 
In addition to examining assessment utilization differences among faculty in various disciplines, it would be useful to investigate if where faculty are based, impacts their assessment practices. Studying how faculty in the field, at regional centers, and on campus utilize the essential assessment practices would be beneficial. One factor that often varies among field, regional, and campus-based faculty is the level of assessment training. It would be valuable to examine how faculty members' levels of training influence their assessment utilization. Studies should also examine how educational attainment and years of professional experience influence assessment utilization. These factors could contribute to a better understanding of the differences in assessment utilization among faculty.

In order to glean more data about assessment practices, future research might examine assessment from the learners' perspective. It would be interesting to ask learners about certain assessment practices of their instructors to see how that compares to how faculty actually described their practices. Since learner resistance was identified as a challenge of assessment, future research could investigate this barrier. Inquiries could be made with regard to how learners feel about assessment in terms of their acceptance of and involvement in the assessment process.

Other studies could consider the perspectives of administrators or stakeholders regarding assessment. Since the lack of administration support was identified as a major barrier for faculty in implementing assessment, research on this obstacle is warranted. The level of involvement and commitment of administrators to effective assessment practices should be determined. 
Finally, this assessment research study should be replicated in five years with the same population. The study would assist in showing growth or decline in utilization of the essential assessment practices. It could also demonstrate impacts of additional assessment training and efforts on faculty perceptions and practices.

\section{Recommendations for Future Practice}

This assessment study resulted in findings which should be used to make necessary modifications in practice. Although these recommendations are based on research results from one university, other institutions should adapt these suggestions as well.

In order to improve assessment utilization, it is recommended that administrators within higher education institutions and assessment leaders implement a number of practices. Higher education institutions should first adopt and use the four essential elements of effective assessment outlined by Huba and Freed (2000) since the current research study has shown gaps in some of the vital practices. When the assessment processes are aligned with the writings of the assessment scholars, a more effective effort should result. Administrators should take the leadership role in promoting assessment by working with faculty to understand and be able to apply assessment techniques (Huba \& Freed, 2000). This would add credibility to the process and provide faculty with a better basis for assessment utilization.

Since this study illuminated ambiguity in the assessment process, it is apparent that leaders, in collaboration with faculty, should develop clear assessment policies and procedures. This will provide guidance and structure for faculty to implement effective, 
ongoing assessment programs. Developing assessment policies will also be useful in selecting, training, and supporting new faculty.

It would also be useful if more support and value were given to the assessment process by administration since this was identified as a crucial barrier by faculty. This encouragement and motivation from administration is necessary to make this paradigm shift. Faculty must be given good reasons to change their current approaches as well as to trust the administrators who are encouraging the transformations (Huba \& Freed, 2000). Since the current research provides insight into the practices and perceptions of faculty, administrators are now better equipped to understand and respond to their faculty.

Administrators may also want to consider making resources readily available to faculty in order to effectively implement assessment. Since faculty identified their lack of secretarial support as a major challenge, assistance for entering and analyzing assessment data should be made available. Administration should also demonstrate their commitment by providing funding for assessment resources and materials.

Since lack of training was determined to be a key barrier to utilization, administrators should examine and implement more effective training strategies. To better meet the needs of individual faculty, the trainings should be tailored to faculty in diverse disciplines. This is so essential due to the significant differences that existed in this study among faculty in different disciplines with regard to specific assessment practices.

It may also be useful to offer rewards and incentives to encourage faculty participation in assessment efforts. Administration and assessment leaders must 
determine what types of rewards motivate the faculty at their institutions. Effective rewards for faculty might include release time, money or recognition for their efforts.

A final administration-related recommendation for practice would be for the leaders to make certain that they are appropriately using the results of assessment efforts. In order for faculty to be motivated to participate, it is essential that the results be used in ways that are beneficial and not professionally harmful. It is hopeful that assessment results might be used for organizational decision-making purposes, with external stakeholders to garner support and/or funding, and for improving the organization as a whole.

In addition to recommendations for changes in practice among administrators, there are a number of suggestions for the assessment practices of faculty. First and foremost, faculty should realize that assessment is not an unconnected, detached activity that involves extra work. Assessment must be viewed as the central basis for planning and promoting student learning, not as an external requirement.

In order to make this cultural shift, faculty should be encouraged to try new strategies. This will require faculty to take risks and become learners themselves by having to ask questions about their new teaching practices (Huba \& Freed, 2000). This requires a cultural shift that represents modifications in how faculty normally function (Eisenman, 1991).

After changing their view of assessment, the faculty must become involved in the process. In general, the results from the current study indicated that a lack of faculty involvement in the process might have been present. The faculty ownership and 
involvement is essential for success and should be improved throughout all of the steps of the assessment process.

Since this research study revealed a significant lack of collaboration among faculty for assessment practices, the need to expand collaboration efforts is obvious. The faculty should examine why they were unsuccessful at collaborating in certain assessment practices such as developing measures, creating educational experiences, and using assessment results. The faculty must view the assessment process not from an individual perspective but as a cultural shift that must involve all members of the educational community. The assessment process should not only involve faculty, administrators, and students but include individuals from outside of the institution (AAHE, 1992).

Since this research study revealed that learner resistance often served as a challenge to effective assessment utilization, faculty should develop strategies for fostering assessment acceptance among learners. In order for the learners to value the assessment process, faculty must demonstrate their commitment to assessment. It must be seen as a natural component of the learning process which will motivate learners to accept assessment (Palomba \& Banta, 1999).

Other implications for practice include faculty closely examining and attempting to overcome the challenges to assessment that were illuminated through this research study. Specifically, faculty should work together to improve the value and merit of conducting assessment with their own colleagues and administrators.

In general, the results of this research study should enable administrators and assessment leaders to develop more effective strategies for garnering and securing faculty 
support for and involvement in assessment efforts. The findings should be of benefit to faculty in order to design strategies to improve their practices. This in turn could lead to successful assessment efforts to improve educational programs as well as accountability efforts within institutions of higher education. 


\section{References}

American Association for Higher Education (AAHE). (1992). Principles of good practice for assessing student learning. Retrieved October 6, 2002 from http://www.aahe.org/principl.htm.

Angelo, T. A. (2002). Engaging and supporting faculty in the scholarship of assessment: Guidelines from research and best practice. In T.W. Banta \& Associates (Eds.), Building a scholarship of assessment (pp. 185-200). San Francisco: Jossey-Bass.

Arnold, M. E. (2002). Be "logical" about program evaluation: Begin with learning assessment. Journal of Extension, 40(3). Retrieved October 18, 2002, from http://www.joe.org/joe/2002june/a4.html.

Bailey, S. J., \& Deen, M. Y. (2002). A framework for introducing program evaluation to Extension faculty and staff. Journal of Extension, 40(2). Retrieved October 18, 2002, from http://www.joe.org/joe/2002april/iw1.html.

Banta, T. W. (1993a). Summary and conclusion: Are we making a difference? In T. W. Banta and Associates (Eds.), Making a difference: Outcomes of a decade of assessment in higher education (pp. 357-376). San Francisco: Jossey-Bass.

Banta, T. W. (1993b). Toward a plan for using national assessment to insure continuous improvement of higher education. The Journal of General Education, 42 (1), 33-52.

Banta, T. W. (1997). Moving assessment forward: Enabling conditions and stumbling blocks. In P. J. Gray \& T.W. Banta (Eds.), The campus-level impact of assessment: Progress, problems, and possibilities (pp. 79-91). San Francisco: Jossey-Bass.

Banta, T. W. (2002). A call for transformation. In T.W. Banta \& Associates (Eds.), Building a scholarship of assessment (pp. 284-292). San Francisco: Jossey-Bass. 
Banta, T. W., Lund J. P., Black, K. E., \& Oblander, F. W. (1996). Assessment in practice: Putting principles to work on college campuses. San Francisco: Jossey-Bass.

Bloom, B. S. (1956). Taxonomy of educational objectives: The classification of educational goals, Handbook I: Cognitive domain. New York: D. McKay.

Bozylinsky, G. (2001). SPSS techniques series: Statistics on Likert scale surveys. Retrieved July 18, 2003, from University of North Iowa, Information Technology Web site: http://www.uni.edu/its/us/document/stats/spss2.html.

Brakke, D. F., \& Brown, D. T. (2002). Assessment to improve student learning. New Directions for Higher Education, 119, 119-122.

Browne, J. L., \& Kiernan, N. E. (1998). A model for integrating program development and evaluation. Journal of Extension, 36(3). Retrieved March 5, 2002, from http://www.joe.org/joe/1998june/rb5.html.

Bush, C., Mullis, R., \& Mullis, A. (1995). Evaluation: An afterthought or an integral part of program development. Journal of Extension, 33(2). Retrieved March 4, 2002, from http://www.joe.org/joe/1995april/a4.html.

Caffarella, R. S. (1994). Planning programs for adult learners: A practical guide for educators, trainers, and staff developers. San Francisco: Jossey-Bass.

Carnegie Foundation. (2003). Carnegie classification of institutions of higher education.

Retrieved October 4, 2003, from http://www.carnegiefoundation.org/Classification/ CIHE2000/PartIfiles.htm.

Chapman-Novakofski, K., Boeckner, L. S., Canton, R., Clark, C. D., Keim, K., \& Britten, P., et al. (1997). Evaluating evaluation- What we've learned. Journal of Extension, 35(1). Retrieved October 18, 2002, from http://www.joe.org/joe/ 1997february/rb2.html.

Cote, C. B., \& Jordan, M. (2002). Effective assessment and institutional change. New 
Directions for Higher Education, 119, 45-49.

Coughlin, M. A., \& Pagano, M. (1997). Case study applications of statistics in institutional research. Tallahassee, FL: Association for Institutional Research.

Cronk, B. C. (1999). How to use SPSS R. Los Angeles: Pyrczak Publishing.

Eisenman, C. D. (1991). Faculty participation in assessment programs. NCA Quarterly, 66, 458-464.

Ewell, P. T. (1983). Information on student outcomes: How to get it and how to use it. Boulder, CO: National Center for Higher Education Management Systems.

Ewell, P. T. (1991). To capture the ineffable: New forms of assessment in higher education. In G. Grant, (Ed.). Review of research in education, 17, 75-125. Washington, DC: American Educational Research Association.

Ewell, P. T. (1993). The role of states and accreditors in shaping assessment practice. In T.W. Banta \& Associates (Eds.), Making a difference: Outcomes of a decade of assessment in higher education (pp. 339-356). San Francisco: Jossey-Bass.

Ewell, P. T. (2002). An emerging scholarship: A brief history of assessment. In T. W. Banta \& Associates (Eds.), Building a scholarship of assessment (pp. 3-25). San Francisco: Jossey-Bass.

Flick, U. (1998). An introduction to qualitative research. Thousand Oaks: Sage.

Fraenkel, J. R., \& Wallen, N. E. (2000). How to design \& evaluate research in education ( $4^{\text {th }}$ ed.). Boston: McGraw-Hill Higher Education.

Gay, L. R., \& Airasian, P. (2000). Educational research: Competencies for analysis and application $\left(6^{\text {th }}\right.$ ed.). Upper Saddle River: NJ: Prentice-Hall, Inc.

Glesne, C. (1999). Becoming qualitative researchers: An introduction. New York: Longmen. Gray, P. J. (1997). Viewing assessment as an innovation: Leadership and the change process. 
In P. J. Gray \& T.W. Banta (Eds.), The campus-level impact of assessment: Progress, problems, and possibilities (pp. 5-15). San Francisco: Jossey-Bass.

Gray, P. J. (2002). The roots of assessment: Tensions, solutions, and research directions. In T.W. Banta \& Associates (Eds.), Building a scholarship of assessment (pp. 4966). San Francisco: Jossey-Bass.

Hadden, C., \& Davies, T. G. (2002) From innovation to institutionalization: The role of administrative leadership in the assessment process. Community College Journal of Research and Practice, 26, 243-260.

Huba, M. E., \& Freed, J. E. (2000). Learner-centered assessment on college campuses: Shifting the focus from teaching to learning. Needham Heights: Allyn \& Bacon.

Jacobi, M., Astin, A., \& Ayala, F. (1987). College student outcomes assessment: A talent development perspective. College Station, TX: Association for the Study of Higher Education.

Krathwohl, D. R., Bloom, B. S., \& Masia, B. B. (1964). Taxonomy of educational objectives: Handbook II: Affective domain. New York: D. McKay.

Magruder, J., McManis, M. A., \& Young, C. C. (1997). The right idea at the right time: Development of a transformational assessment culture. In P. J. Gray \& T.W. Banta (Eds.), The campus-level impact of assessment: Progress, problems, and possibilities (pp. 17-29). San Francisco: Jossey-Bass.

Marshall, C., \& Rossman, G. B. (1995). Designing qualitative research. Thousand Oaks: Sage.

Merriam, S. B. (1988). Case study research in education: A qualitative approach. San Francisco: Jossey-Bass.

Muffo, J. A. (1992). The status of student outcomes assessment at NASULGC member 
institutions. Research in Higher Education, 33, 765-774.

National Association of State Universities and Land-Grant Colleges. (2001). Strategic directions of the Cooperative Extension System. Retrieved October 20, 2002, from http://www.nasulgc.org/publications/Agriculture/CES_Strategic.htm.

Ory, J. C., \& Parker, S. A. (1989). Assessment activities at large, research universities. Research in Higher Education, 30, 375-385.

O’Sullivan, E., \& Rassel, G. R. (1995). Research methods for public administrators. White Plains, NY: Longman.

Palomba, C. A. (1997). Assessment at Ball State University. In P. J. Gray \& T.W. Banta (Eds.), The campus-level impact of assessment: Progress, problems, and possibilities (pp. 31-45). San Francisco: Jossey-Bass.

Palomba, C. A., \& Banta, T. W. (1999). Assessment essentials: Planning, implementing, and improving assessment in higher education. San Francisco: Jossey-Bass.

Patton, M. Q. (1990). Qualitative evaluation and research methods. Newbury Park: Sage Publications.

Peshkin, A. (1988). In search of subjectivity- One's own. Educational Researcher, 17-21.

Peterson, M. W., \& Augustine, C. H. (2000). Organizational practices enhancing the influence of student assessment information in academic decisions. Research in Higher Education, 41(1), 21-52.

Peterson, M. W., \& Einarson, M. K. (2001). What are colleges doing about student assessment? Does it make a difference? The Journal of Higher Education, 72, 629-669.

Peterson, M. W., \& Vaughan, D. S. (2002). Promoting academic improvement. In T.W. Banta \& Associates (Eds.), Building a scholarship of assessment (pp. 131-147). San Francisco: Jossey-Bass. 
Pike, G. R. (2002). Measurement issues in outcomes assessment. In T.W. Banta \& Associates (Eds.), Building a scholarship of assessment (pp. 131-147). San Francisco: Jossey-Bass.

Prawl, W., Medlin, R., \& Gross, J. (1984). Adult and continuing education through the Cooperative Extension Service. Columbia, MO: University Printing Services.

RiCharde, R. S., Olney, C. A., \& Erwin, T. D. (1993). Cognitive and affective measures of student development. In T.W. Banta \& Associates (Eds.), Making a difference: Outcomes of a decade of assessment in higher education (pp. 179-195). San Francisco: Jossey-Bass.

Rosenthal, B. (2000). Impact analyses: Concepts and methods. Paper presented at the Annual Meeting of the Association for Institutional Research, Cincinnati, $\mathrm{OH}$. (ERIC Document Reproduction Service No. ED446503)

Schultz, R. A. (2002). Apples, oranges, and assessment. Arts Education Policy Review, 103(3), 11-16.

Strauss, A., \& Corbin, I. (1990). Basics of qualitative research: Grounded theory procedures and techniques. Newbury Park: Sage.

Suskie, L. A. (1996). Questionnaire survey research (2 ${ }^{\text {nd }}$ ed.). Tallahassee, FL: Association for Institutional Research Resources for Institutional Research.

Tuckman, B. W. (1999). Conducting educational research. Belmont, CA: Wadsworth Group/Thomson Learning.

United States Department of Agriculture. (1983). Challenge and change: A blueprint for the future- Extension Service, USDA. Washington, DC: United States Department of Agriculture.

United States Department of Agriculture (2002). Administrative handbook for Cooperative Extension work. Retrieved October 20, 2002, from 
http://www.reeusda.gov/hrd/cesguide/partnership.htm.

Warner, P. D., \& Christenson, J. A. (1984) The Cooperative Extension Service: A national assessment. Boulder, CO: Westview Press.

West Virginia University. (1979). Program evaluation in Extension: A comprehensive study of methods, practices, and procedures. Morgantown, WV: Office of Research and Development.

White, B. A., \& Burnham, B. (1995). The Cooperative Extension System as a facilitator of access for community-based education. Washington, DC: U.S. Department of Education.

Williford, A. M. (1997). Ohio University's multidimensional institutional impact and assessment plan. In P. J. Gray \& T.W. Banta (Eds.), The campus-level impact of assessment: Progress, problems, and possibilities (pp. 47-57). San Francisco: Jossey-Bass. 
APPENDIX A

Permission Letter To Conduct Study 
December 11, 2002

\section{To Whom It May Concern:}

On behalf of Maryland Cooperative Extension, I strongly support and approve of the research that Jennifer Thorn is conducting regarding the current assessment practices of our faculty. I understand that this research study is being conducted as part of her doctoral dissertation in Educational Leadership Studies at West Virginia University.

I give my permission for Jennifer Thorn to administer surveys in the spring of 2003 to all Maryland Cooperative Extension faculty who choose to participate in the study. I understand that the survey will examine the differences in assessment utilization among faculty of various ranks and disciplines while identifying what faculty believe are the benefits and challenges of implementing assessment.

Since the results of this study will be valuable for improving our assessment efforts, I also give permission for Maryland Cooperative Extension to be identified in the study as long as the confidentiality of individual responses and individual faculty names will be guaranteed. It is also understood that this study will undergo human subjects review by the West Virginia University Institutional Review Board.

Sincerely,

James Wade, Ph.D.

Associate Dean \& Associate Director 
APPENDIX B

Pilot Cover Letter To Participants 
February 1, 2003

\section{Dear Colleague:}

Maryland Cooperative Extension (MCE) has recently made an effort to expand faculty use of program evaluation/assessment techniques across all disciplines. I have participated in this effort as part of MCE's evaluation team which piqued my interest to formally study the phenomenon as part of my doctoral dissertation in Educational Leadership Studies at West Virginia University.

Your input is very important in this study that will involve all MCE faculty in examining the existing assessment practices across the state. For purposes of this inquiry, assessment is defined as gathering information from various sources to determine how learners' knowledge, attitudes, and behaviors have changed as a result of their educational experiences. The study will examine the differences in assessment utilization among faculty of various ranks and disciplines while identifying what faculty believe are the benefits and challenges of implementing assessment.

This study will allow you to share your thoughts about assessment in MCE so that necessary improvements can be made in the process. Please complete the enclosed survey which should take no more than 15 minutes. After completing the survey, please attach a sample of learner outcomes from one class (this includes statements of what your participants should know and/or be able to do following participation in your class/program). Also attach one of your end-ofclass tests (directly measures changes in participant knowledge/attitudes) or a survey (indirectly measures changes in knowledge/attitude/behavior as self-reported by participants). Please use the self-addressed, stamped envelope to return your survey and documents by February 20, 2003.

Your participation in this study is completely voluntary and your job status will not be affected by refusal to participate. You do not have to respond to every item on the survey and the confidentiality of your responses will be assured since no individual names or responses will be disclosed at any time. The number on the survey will simply be used to contact and remind those not returning the survey. Dr. James Wade, Associate Director of MCE as well as West Virginia University's Institutional Review Board have approved this study.

Thanks in advance for taking your valuable time to participate in the study! Without your cooperation and assistance, this research would not be possible. When the study is completed, I will provide you with a summary of the research findings. If you have any questions, please feel free to contact me at MCE of Garrett County at 301-334-6960 or via email at jthorn @.umd.edu.

Sincerely,

Jennifer D. Thorn, M.Ed., R.D.

WVU Doctoral Candidate 


\section{APPENDIX C}

Pilot Survey of Assessment Utilization by Extension Faculty 


\section{Survey of Assessment Utilization by Extension Faculty}

For a copy of the survey, please contact:

Jennifer Thorn Bentlejewski, Ed.D.

P.O. Box 746

McHenry, MD 21541

301-616-9445

301-334-6960

jthorn@umd.edu 
APPENDIX D

Cover Letter To Pilot Participants 
January 20, 2003

Dear

Thank you for your willingness to participate in the pilot study examining assessment practices among Extension faculty in which I discussed with you by telephone on January X, 2003. You are one of six West Virginia University Extension faculty participating in this pilot. There are two selected faculty from each of the disciplines of agriculture, youth development, and family and consumer sciences. This study is part of my doctoral dissertation in Educational Leadership Studies at West Virginia University.

Please read the cover letter as if you were participating in the actual study. Then, complete the "Survey of Assessment Utilization by Extension Faculty". Feel free to make notes regarding any inconsistencies or problems that you find with the cover letter or survey. I will then schedule a time with you to conduct a short interview so that you can share any suggestions that you might have for improvement.

Your input is so essential to the success of this assessment research. Thanks so much for taking your time to participate in this pilot study! If you have any questions, please feel free to contact me at Maryland Cooperative Extension of Garrett County at 301-334-6960 or via email at jt118@umail.umd.edu.

Sincerely,

Jennifer D. Thorn, M.Ed., R.D.

WVU Doctoral Candidate 


\section{APPENDIX E}

Pilot Study Interview Questions 


\section{Pilot Study Interview Questions}

Thank you for taking the time to complete my "Survey of Assessment Utilization By Extension Faculty.” Today, I would like to ask you a few questions about the survey to help strengthen it for the actual study with Maryland Cooperative Extension faculty.

\section{Cover Letter}

1. Was the purpose of my research clear in the cover letter?

2. Were the potential benefits of the study obvious in the cover letter?

3. Were you motivated to complete the survey after you read the cover letter?

4. Was the cover letter easy to read and understand?

5. Were the instructions for returning the survey clear?

6. Was anything missing in the cover letter?

\section{Survey}

1. Were the instructions clear on the survey?

2. Were any questions difficult to answer? Why?

3. Were there any terms that you did not understand?

4. Did the organization of the survey make sense and flow smoothly?

5. How long did it take you to complete the survey?

6. Do you have any other suggestions for improvement?

Thanks so much for your assistance in improving this study of assessment practices! 
APPENDIX F

Final Version of Cover Letter to Participants 
April 1, 2003

Dear «Prefix» «LastName»:

I am conducting a study of Maryland Cooperative Extension (MCE) faculty involvement in performing assessments of their programs and I am asking for your participation. MCE has recently made an effort to expand faculty use of program assessment techniques. I am interested in studying this phenomenon as part of my doctoral dissertation in Educational Leadership Studies at West Virginia University (WVU).

Your input is very important in this study that will involve all faculty with MCE appointments in examining their assessment practices. For purposes of this inquiry, assessment is defined as a process in which faculty gather information about how their learners' knowledge, attitudes, and behaviors have changed as a result of participating in Extension education experiences. The study will examine the differences in assessment utilization among faculty of various ranks and disciplines and will identify faculty perceptions of the benefits and challenges of implementing assessment. Dr. James Wade, Associate Director of MCE as well as WVU's Institutional Review Board have approved this study.

The study will allow you to share your thoughts about assessment so that improvements can be made to MCE's assessment training efforts as well as other organizational processes. Your responses will be confidential since no individual answers or documents will be shared at any time. You do not have to respond to every item on the survey. Your participation in this study is completely voluntary, and your job status will not be affected by your refusal to participate.

- Please complete the enclosed survey which should take no more than 15 minutes.

- Attach one assessment measure such as an end-of-class test (directly measures changes in participant knowledge/attitudes) or a survey (indirectly measures changes in knowledge/ attitudes/behaviors as self-reported by participants).

- Use the self-addressed, stamped envelope to return your survey and one sample of an assessment measure by April 15, 2003.

Thanks in advance for taking your valuable time to participate in the study! For those who participate, I will provide a summary of the research findings. If you have any questions, please contact me at 301-334-6960 or via email at jthorn@umd.edu.

Sincerely,

Jennifer D. Thorn, M.Ed., R.D.

WVU Doctoral Candidate 


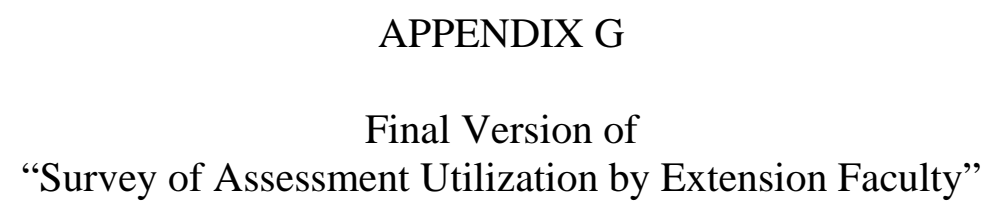




\section{Survey of Assessment Utilization by Extension Faculty}

For a copy of the survey, please contact:

Jennifer Thorn Bentlejewski, Ed.D.

P.O. Box 746

McHenry, MD 21541

301-616-9445

301-334-6960

jthorn@umd.edu 